\title{
LA RELACIÓN DE LA CORTE PENAL INTERNACIONAL CON EL PROCESO DE PAZ EN COLOMBIA
}

Luísa Brandão Bárrios*

\begin{abstract}
Resumen: La Corte Penal Internacional (CPI, en adelante) adoptada el 17 de julio de 1998, con sede en La Haya (Holanda), es un tribunal permanente, con vocación universal, de carácter complementario respecto de las jurisdicciones nacionales, fue creada en respuesta a los genocidios, crímenes de lesa humanidad y crímenes de guerra, y recientemente, crímenes de agresión, cometidos durante el siglo Xx, para que tales crímenes no queden sin castigo, a efectos de poner fin a la impunidad. La CPI tiene jurisdicción desde el 1. ${ }^{\circ}$ de noviembre de 2002, para conocer de los demás crímenes contemplados en el Estatuto de Roma presuntamente cometidos en Colombia o por colombianos, a saber, genocidio y crímenes de lesa humanidad, para tal, y teniendo en cuenta que ciertas disposiciones del Estatuto eran diferentes a las de tradición jurídica nacional, fue necesario primero reformar la Constitución Política, más específicamente mediante el Acto Legislativo 02 de 2001, que adicionó el artículo 93 de la Norma Superior. En este trabajo abordaremos la posición de Colombia frente a tales atrocidades y el papel que desempeña la CPI con la Jurisdicción Especial para la Paz, frente a la justicia transicional en Colombia.
\end{abstract}

* Licenciada en Derecho por la Universidad Lusíada de Oporto (Portugal). Doctora en Derecho y estudiante de posdoctorado en la Universidad de Salamanca.Correo-e: luisabarrios@icloud.com.Fecha de recepción: 14 de marzo de 2020. Fecha de aceptación: 12 de enero de 2021. Para citar el artículo: LuísA BRANDÃo BÁRrios. "La relación de la Corte Penal Internacional con el proceso de paz en Colombia”, Revista Derecho Penal y Criminología, vol. 41, n. . 110, enero-junio de 2020, Bogotá, Universidad Externado de Colombia, pp. 119-160. DoI: https://doi.org/10.18601/01210483.v41n110.06. 
Palabras clave: Corte Penal Internacional; Corte Constitucional colombiana; crímenes de guerra y crímenes contra la humanidad; Jurisdicción Especial para la Paz; justicia transicional.

\title{
THE RELATIONSHIP OF THE INTERNATIONAL CRIMINAL COURT WITH THE PEACE PROCESS IN COLOMBIA
}

\begin{abstract}
The International Criminal Court (ICC, hereinafter) adopted on July 17, 1998, based in The Hague, The Netherlands, is a permanent court, with a universal vocation, of a complementary nature with respect to national jurisdictions, was created in response to genocides, crimes against humanity and war crimes, and recently, crimes of aggression, committed during the twentieth century, so that such crimes do not go unpunished, in order to end impunity. The ICC has jurisdiction since November 1, 2002, to hear of the other crimes contemplated in the ER allegedly committed in Colombia or by Colombians, namely genocide and crimes against humanity, for such, and taking into account, that certain ER provisions were different from those of national legal tradition, they should first reform the Political Constitution, more specifically, the "legislative act" 02 of 2001, which added article 93 of the Superior Standard. In this paper we will address Colombia's position in the face of such atrocities and the role that the ICC plays with the Special Jurisdiction for Peace, in the face of transitional Justice in Colombia.
\end{abstract}

Keywords: International Criminal Court; Colombian Constitutional Court; war crimes and crimes against humanity; Special Jurisdiction for Peace; transitional justice.

\section{LA CORTE PENAL INTERNACIONAL, EL ESTATUTO DE ROMA Y LEGISLACIÓN INTERNA COLOMBIANA}

El Estatuto de Roma (ER, en adelante) se basa en la convicción de que el enjuiciamiento efectivo de tales crímenes contribuirá a su prevención. Al acordar un ordenamiento jurídico común para proteger a los individuos y las comunidades de las atrocidades masivas, los Estados Partes del ER promueven la paz y la seguridad internacional.Los principios del ER reflejan el consenso de la comunidad internacional sobre el papel esencial que la justicia cumple en la creación de una paz sostenible.

Ciertas disposiciones del ER eran diferentes a las de tradición jurídica nacional colombiana, para tal, fue necesario primero reformar la Constitución Política, más específicamente mediante el Acto Legislativo 02 de 2001, que adicionó el artículo 93 de la Norma Superior, en los siguientes términos: 
El Estado colombiano puede reconocer la jurisdicción de la Corte Penal Internacional en los términos previstos en el Estatuto de Roma [...] La admisión de un tratamiento diferente en materias sustanciales por parte del Estatuto de Roma con respecto a las garantías contenidas en la Constitución tendrá efectos exclusivamente dentro del ámbito de la materia regulada en él.

En la tradición constitucional colombiana, un acto legislativo es una norma expedida por el Congreso de la República que tiene por objeto modificar, reformar, adicionar o derogar textos de carácter constitucional. Esta facultad está consagrada en la misma Constitución y en el Reglamento del Congreso (Ley 5 de 1992) ${ }^{1}$.

A partir de esta disposición constitucional, Colombia aprobó el ER mediante la Ley 742 de 2002, declarada exequible por la Corte Constitucional mediante su sentencia C- $578^{[2]}$ del mismo año.

El 5 de agosto de 2002 Colombia ratificó el ER, y también es parte del Acuerdo sobre Privilegios e Inmunidades de la CPI (Ley 1180 de 2007) ${ }^{3}$, e introdujo, además, las Reglas de Procedimiento y Prueba y los Elementos de los Crímenes del Estatuto de Roma de la Corte Penal Internacional (Ley 1268 de 2008) ${ }^{4}$.

En la actualidad, 123 Estados Miembros son parte del sistema de justicia internacional penal del Estatuto de Roma, y se han comprometido colectivamente a llevar a rendir cuentas a los responsables de crímenes de atrocidad masiva, aun cuando hubiesen sido cometidos en su propio territorio.

La CPI reconoce la importante función que cumple el Consejo de Seguridad de las Naciones Unidas (CSNU), el máximo órgano de decisión de la ONU, cuya misión es mantener la paz y la seguridad internacional. En este aspecto, el CSNU puede remitir casos o situaciones por medio de una resolución a la Corte para su análisis e investigación. La CPI cuenta solamente con financiación de los Estados Parte, donaciones voluntarias de los gobiernos, individuos, corporaciones y otras entidades.

Un aspecto importante para destacar es que ésta no cuenta con un órgano policivo para el arresto de los acusados ni la custodia de los condenados. Por ello, la CPI ha resaltado la importancia de la cooperación de todos los Estados sobre este punto.

La Corte está compuesta de cuatro órganos, dos oficinas semiautónomas y el Fondo para las Víctimas (The Trust Fund for Victims [TFV]).

1 Consultar [https://www.oas.org/juridico/spanish/mesicic2_col_ley_5_sp.pdf].

2 Consultar [https://www.corteconstitucional.gov.co/relatoria/2002/C-578-02.htm].

3 Consultar [http://www.suin-juriscol.gov.co/viewDocument.asp?ruta=Leyes/1675282].

4 Consultar [http://www.suin-juriscol.gov.co/viewDocument.asp?ruta=Leyes/1676652]. 
Los órganos son: Presidencia, Divisiones Judiciales, Oficina del Fiscal y Secretaría.

- Presidente: juez Chile Eboe-Osuji (Nigeria)

- Primer vicepresidente: juez Robert Fremr (República Checa)

- Segundo vicepresidente: juez Marc Perrin de Brichambaut (Francia)

- Dieciocho jueces organizados dentro de la División de Cuestiones-Preliminares, la División de Juicio y la División de Apelaciones

- Fiscal: Fatou Bensouda (Gambia)

- Vicefiscal: James Stewart (Canadá)

- Secretario: Peter Lewis (Gran Bretaña)

- Las oficinas semiautónomas son la Oficina del Abogado Público para Víctimas y la Oficina del Abogado Público para la Defensa

En términos generales, el procedimiento para la aprobación de uno de estos actos es más exigente que para expedir una ley. Mientras que una ley normal debe surtir cuatro debates, los actos legislativos deben pasar ocho.

\subsection{La CPI en colaboración con la Jurisdicción Especial para la Paz en Colombia}

El Acuerdo entre la Republica de Colombia y la Corte Penal Internacional sobre la Ejecución de las Penas Impuestas por la Corte Penal Internacional fue ratificado mediante Ley 1662 de $2013^{[5]}$ y objeto de control automático por parte de la Corte Constitucional colombiana mediante sentencia C-339 de $2014^{[6]}$, puesto que, en desarrollo del principio de cooperación internacional, la Republica de Colombia suscribe este acuerdo con el fin de proveer instrumentos que hagan eficaz la jurisdicción de la CPI. Al momento de depositar el instrumento de ratificación del ER, Colombia declaró, de conformidad con el artículo 124 del ER, que no aceptaba la competencia de la CPI para procesar a nacionales colombianos que hubiesen cometido crímenes de guerra, o a nacionales de otros países que hubiesen cometido crímenes de guerra en territorio colombiano, antes del $1 .^{\circ}$ de noviembre de 2009.

5 Consultar [http://www.suin-juriscol.gov.co/viewDocument.asp?ruta=Leyes/1685991].

6 Consultar [https://www.corteconstitucional.gov.co/relatoria/2014/C-339-14.htm]. El Acuerdo tiene el propósito de crear un marco regulatorio relativo a los actos y procedimientos de designación de Colombia como Estado de ejecución de penas impuestas por la CPI, de su decisión de aceptar o no tal designación y de los demás aspectos concernientes al proceso de ejecución de la pena propiamente dicha. El cometido del Acuerdo está fundado en una de las previsiones del ER, la cual establece directamente que la CPI puede designar a un Estado de los que se encuentren en disposición de recibir personas condenadas, para que en su territorio se ejecute una pena impuesta por la CPI. 
Colombia ha apoyado, desde su creación, la labor de la CPI, tanto como parte, e introduciendo en su legislación interna los instrumentos legales mencionados supra; también ha promovido el debate y el conocimiento públicos sobre la CPI; ha presidido el Grupo de Amigos de la CPI y ha contribuido voluntariamente al Fondo Fiduciario de Víctimas (TFV, por su sigla en inglés). En la actualidad, y por iniciativa del partido de derecha Centro Democrático, que lidera el expresidente Álvaro Uribe (2002-2010), se busca modificar la Jurisdicción Especial para la Paz (en adelante, JEP, tribunal colombiano creado en los diálogos de paz de La Habana para juzgar a actores del conflicto armado, cuya existencia no podrá ser superior a veinte años) en el Congreso para que se creen salas especiales para magistrados o se designen magistrados que conozcan de temas relacionados con la Fuerza Pública, de manera tal que sean estos los que juzguen a los militares.

La iniciativa de crear salas especiales para los militares, que es materia de diálogo en el Congreso, busca que estos sean juzgados de manera diferenciada a los excombatientes de la guerrilla de las FARC, hoy convertida en partido político de izquierda tras la firma del Acuerdo de Paz con el Gobierno en noviembre de 2016.

La Ley 1922 de $2018^{[7]}$, por medio de la cual se adoptan unas reglas de procedimiento para la Jurisdicción Especial para la Paz, establece en su artículo 72 una cláusula remisoria de acuerdo con la cual en los asuntos no regulados por ella se aplicará la Ley 1592 de 2012, Ley 1564 de 2012, Ley 600 de 2000 y la Ley 906 de 2004, siempre y cuando tales remisiones se ajusten a los principios rectores de la justicia transicional (Ley 1922, 2018). Se subraya que en la sentencia C-112/19 ${ }^{[8]}$ la Corte Constitucional declaró exequibles la mayoría de las normas demandadas, pero estableció algunas condiciones.

No puede olvidarse que el Acuerdo Final de Paz es una normativa vinculante ${ }^{9}$, razón por la cual la falta de mención a este en la cláusula de reenvío no puede interpretarse como una forma de desconocimiento de sus efectos normativos, sino que debe entenderse como una mera omisión del legislador ordinario.

En lo que sigue procederemos a glosar y justificar el fundamento de dicha remisión normativa, las razones del orden que se dio a las leyes que la integran, el ajuste a los principios rectores de la justicia transicional y algunas de las características concretas

7 Alberto Perdomo Poveda. “Algunas consideraciones sobre la cláusula remisoria de la Ley 1922 de 2018, por medio de la cual se adoptan unas reglas de procedimiento para la Jurisdicción Especial para la Paz", en Temas Socio-Jurídicos, 38 (77), 2019, 93-115 (todas las referencias normativas citadas en este párrafo se encuentran citadas por este autor).

8 Consultar [https://www.corteconstitucional.gov.co/relatoria/2019/C-112-19.htm].

9 Alberto Perdomo Poveda. Problemas hermenéuticos de la Ley de Amnistía - Especial referencia a la amnistía de iure consagrada, Bogotá, Ediciones Nueva Jurídica, 2017, 39-45. 
de los trámites y procedimientos que deben aplicar las salas y secciones de la JEP y la calificación inquisitiva, acusatoria o mixta que ellos deben recibir.

Al revisar el contenido de las codificaciones penales de principios del siglo Xx se percibió que no contenían un acápite especial a las normas rectoras, que tienen como finalidad gobernar la interpretación a la hora de definir los asuntos que le corresponden a la JEP, precisan que la efectividad de la justicia restaurativa consiste en "garantizar los presupuestos necesarios para asegurar la reconciliación y el establecimiento de una paz estable y duradera", expresión que coincide en un todo con el mismo nombre del Acuerdo Final de Paz. Es necesario recordar que el documento titulado Acuerdo General para la Terminación del Conflicto y la Construcción de una Paz Estable y Duradera, firmado por los representantes del Gobierno Nacional y los delegados de las FARC-EP en La Habana, el 26 de agosto de 2012, se convirtió en la hoja de ruta que permitió, finalmente, suscribir el Acuerdo Final para la Terminación del Conflicto y la Construcción de una Paz Estable y Duradera, o Acuerdo del Teatro Colón, rubricado el 24 de noviembre de 2016.

La implementación del Acuerdo Final involucra normas de diferente jerarquía, que dan fuerza normativa directa al Acuerdo de Paz. Entre otras, destacamos ${ }^{10}$ : (1) Acto Legislativo 01 de 2012 (por medio del cual se establecen instrumentos jurídicos de justicia transicional en el marco del artículo 22 de la Constitución Política y se dictan otras disposiciones [arts. transits. 66 y 67]); (2) Acto Legislativo 01 de 2016 (por medio del cual se establecen instrumentos jurídicos para facilitar y asegurar la implementación y el desarrollo normativo del acuerdo final para la terminación del conflicto y la construcción de una paz estable y duradera [arts. transits. 68, 69, 70 y 71]); (3) Ley 1820 de 2016 (por medio de la cual se dictan disposiciones sobre Amnistía, Indulto y Tratamientos Penales Especiales); (4) Acto Legislativo 01 de 2017 (por medio del cual se crea un título de disposiciones transitorias de la Constitución para la terminación del conflicto armado y la construcción de una paz estable y duradera y se dictan otras disposiciones - creación de la JEP); (5) Acto Legislativo 02 de 2017 (por medio del cual se adiciona un artículo transitorio a la Constitución con el propósito de dar estabilidad y seguridad jurídica al acuerdo final para la terminación del conflicto y la construcción de una paz estable y duradera; (6) Acto Legislativo 03 de 2017 (Partido de las FARC-EP).

En el 2018, la JEP anunció que investigará los asesinatos extrajudiciales o "falsos positivos" (véase la definición más adelante) cometidos por militares, indicó que los "falsos positivos" se dieron en 29 de los 32 departamentos de Colombia y que el $45 \%$ de las víctimas eran campesinos y el $30 \%$ se dedicaba a actividades productivas informales en las ciudades.

10 Consultar el Acuerdo Final en [https://www.unidadvictimas.gov.co/sites/default/files/documentosbiblioteca/nuevoacuerdofinal.pdf]. 
En 2018, la Sala de Reconocimiento y Verdad de la JEP abrió el caso 001, en el que están vinculados 32 exguerrilleros de las FARC por secuestros cometidos entre 1993 y 2012, y el caso 002, en el que estudiará la situación de violaciones contra derechos humanos en el departamento de Nariño (suroeste).

Según la JEP, los reportes que ha recibido de la Fiscalía dan cuenta de un total de 2248 víctimas entre 1988 y 2014, de las cuales el 48\% fueron hombres entre los 18 y los 30 años. La JEP indicó que para abrir el caso recibió información del Ministerio de Defensa, según la cual 1750 integrantes del Ejército colombiano expresaron su voluntad de acogerse a la justicia transicional tras señalar que están involucrados en casos del conflicto armado.

Para darle prioridad a este caso, la JEP tuvo en cuenta el llamado que hizo la CPI en el marco del examen preliminar que adelanta sobre este tema desde junio de 2004. Por último señaló que la Sala de Reconocimiento y Verdad decidirá quiénes y en qué orden llamará a versión voluntaria a los 1750 militares.

Para entender el papel de la CPI en el proceso de justicia transicional en Colombia, es importante recordar algunas de las actividades realizadas en relación con el examen preliminar de la Fiscalía en esta situación -el fiscal adjunto de la CPI es James Kirkpatrick Stewart.

Un examen preliminar no es una investigación: es un proceso de reunión y análisis de información que permite a la fiscal determinar cuestiones relativas a la competencia y la admisibilidad antes de decidir si existe fundamento razonable para iniciar una investigación.

A la luz de los criterios del ER, la fiscal determinó que existía fundamento suficiente para creer que las FARC-EP, el Ejército de Liberación Nacional (ELN), el Ejército Nacional y los grupos paramilitares habían cometido crímenes de guerra y crímenes de lesa humanidad en Colombia, desde que la competencia de la Corte entró en vigor; sin embargo, no se inició una investigación, en virtud del principio de complementariedad de las jurisdicciones. Se han llevado a cabo procesos nacionales en relación con estos presuntos crímenes, y tales procesos siguen desarrollándose ${ }^{11}$.

Sin embargo, en 2012 la Fiscalía identificó algunas áreas de preocupación, respecto de las cuales eran necesarios mayores esfuerzos judiciales para asegurar que las personas responsables por los crímenes más graves fuesen llevadas a rendir cuentas.

11 Jean Carlo Mejía Azuero. La Corte Penal Internacional y las Fuerzas Armadas de Colombia: una mirada desde la trinchera, Biblioteca Jurídica Diké, 2006. 
Además, la Fiscalía indicó que seguiría los desarrollos legislativos que pudieran tener un impacto sobre los procesos nacionales relativos a los crímenes del ER, como legislación que establezca cualquier tipo de jurisdicción nueva que se encargue de investigar y enjuiciar tales crímenes.

La Fiscalía consideró que aquellas personas dentro de las FARC-EP y el ELN, que presuntamente eran las más responsables por los crímenes más graves, habían sido sometidas a procesos nacionales genuinos. Esta conclusión se alcanzó sobre la base de las condenas dictadas por los tribunales colombianos contra líderes de las FARC-EP y del ELN por conductas relevantes para la competencia de la CPI; sin embargo, la conclusión de la Fiscalía estaba sujeta a la adecuada ejecución de las penas. En otras palabras, en la etapa de examen preliminar, el foco de la Fiscalía es determinar si los casos potenciales identificados por la Fiscalía han sido o están siendo abordados en el ámbito nacional de manera genuina.

Con arreglo al ER, se realizarán procesos genuinos de orden nacional cuando éstos no hayan sido adoptados con el propósito de sustraer a las personas de que se trate de su responsabilidad penal; cuando no haya una demora injustificada en el juicio que sea incompatible con la intención de hacer comparecer a las personas de que se trate ante la justicia; y cuando tales procesos se sustancien de manera independiente e imparcial de forma que sea compatible con la intención de hacer comparecer a las personas ante la justicia.

Si estos criterios, respecto de la voluntad genuina de investigar se cumplen, entonces los casos no son admisibles ante la CPI y la Fiscalía no intervendrá. La evaluación de si una actuación es genuina necesariamente se refiere a los procesos nacionales específicos en casos puntuales, no a los mecanismos de justicia transicional o al sistema judicial nacional en su conjunto. En última instancia, al evaluar los procesos nacionales concretos, la Fiscalía tomará en consideración si las autoridades nacionales competentes están adoptando medidas concretas y progresivas de investigación o enjuiciamiento dirigidas a determinar la responsabilidad de individuos que posiblemente tengan la mayor responsabilidad por los crímenes más graves. Esta evaluación abarca todas las etapas relevantes de los procesos concretos, desde la investigación hasta el juicio y la apelación.

La situación en Colombia es objeto de examen preliminar por parte de la Oficina de la Fiscalía de la CPI (OTP, por su sigla en inglés) desde junio de 2004. Al respecto, la ОТР indicó, en su Reporte Intermedio sobre la situación en Colombia de noviembre de $2012^{[12]}$, que el examen preliminar de la situación en Colombia se centrará en:

12 Consultar [https://www.coljuristas.org/documentos/adicionales/cpi-situacion_en_colombia-2012_nov. pdf]. 
- el seguimiento del Marco Legal para la Paz y otros desarrollos legislativos pertinentes, así como los aspectos jurisdiccionales relacionados con el surgimiento de "nuevos grupos armados ilegales";

- las actuaciones judiciales relacionadas con la promoción y expansión de grupos paramilitares;

- las actuaciones judiciales relacionadas con el desplazamiento forzado;

- las actuaciones judiciales relacionadas con crímenes sexuales;

- los casos de "falsos positivos" -los asesinatos de civiles escenificados para parecer muertes en combate- son uno de los episodios más oscuros del conflicto armado en Colombia. "Positivos" es una expresión que se usa en el mundo militar cuando se tiene éxito en una misión; "falso positivo", cuando se presenta como "positivo" una baja/muerte, la cual no ha sido ni en combate, ni en persona beligerante en cualquier conflicto: los fallecidos eran presentados por el ejército como guerrilleros muertos en combate con el objetivo de obtener de sus superiores beneficios en forma de ascensos, condecoraciones o permisos.

\subsubsection{Breve referencia a los "falsos positivos"13}

Actualmente no hay un consenso en la categorización jurídica de los denominados "falsos positivos" una vez que en algunas ocasiones se habla de "ejecuciones extrajudiciales", en otras de "homicidio en persona protegida" y en otros casos de "desapariciones forzadas", dependiendo de la institución que los juzgue. Se hace imprescindible la integración de conceptos para crear seguridad jurídica en el derecho administrativo colombiano en cuanto a la responsabilidad extracontractual del Estado.

El concepto de reparación adoptado en derecho administrativo colombiano no siempre coincide con los estándares delineados por el sistema interamericano de protección de derechos humanos, lo cual repercute de manera negativa en el tratamiento dado a las víctimas de los "falsos positivos". Esto hace necesario el estudio detallado de las decisiones propias de cada sistema y compararlas para buscar mejorar los estándares nacionales de reparación.

Unificando los criterios de calificación jurídica de los "falsos positivos" se producirá un avance en el ámbito del derecho administrativo colombiano, porque esta calificación hace más expedita e inequívoca la aplicación de la convención interamericana

13 Juan Sebastián Quintero Mendoza. Las desapariciones forzadas y los “falsos positivos": del derecho internacional al derecho administrativo colombiano, Bogotá, Universidad del Rosario, 2016; Viridiana Molinares Hassan. Guerra irregular y constitucionalismo en Colombia, Barranquilla, Universidad del Norte, 2014 (siendo estos dos libros los utilizados para el punto 1.1.1. de este trabajo). 
sobre desaparición forzada y la jurisprudencia de la Corte Interamericana en las sentencias del Consejo de Estado.

Las desapariciones sistemáticas encarnan aún hoy la memoria más viva del conflicto y afectan a miles de familias. Por eso el trabajo de instituciones como la JEP o la Unidad de Búsqueda es clave para tratar de cerrar este caso. Las ejecuciones extrajudiciales solo representan un porcentaje de casos sin resolver.

En medio de una amalgama de estimaciones sobre las miles de víctimas de ese procedimiento, los datos oficiales ofrecidos por la Fiscalía indican que entre 1998 y 2014 hubo más de 2200 ejecuciones de este tipo. La inmensa mayoría, durante los dos mandatos del entonces presidente Álvaro Uribe (2002-2010).

En el año 2012 la Fiscalía señala, respecto a los casos de "falsos positivos", que se habían iniciado una serie de investigaciones. Sin embargo, los procesos que habían sido iniciados hasta ese momento no parecían haberse centrado en las personas que podrían tener mayor responsabilidad dentro de la jerarquía militar. Desde entonces, la situación ha evolucionado, y la Fiscalía General de la Nación ${ }^{14}$ ha estado llevando a cabo una serie de procesos para determinar la responsabilidad de las autoridades militares de alto nivel por los asesinatos conocidos como "falsos positivos", tomando en consideración este desarrollo a los efectos de determinar si existen procesos nacionales genuinos que estén abordando casos potenciales para la CPI que surjan de la situación en Colombia.

La Fiscalía identifica casos potenciales sobre la base de criterios que incluyen: la identificación de personas, o grupos de personas que presuntamente estuvieron involucradas en lo que probablemente constituya el foco de una investigación de la CPI, y los crímenes de competencia de la CPI presuntamente cometidos durante incidentes que probablemente constituyan el foco de una investigación, a los efectos de delinear casos futuros. Este análisis es, por definición, solo de naturaleza preliminar y se realiza a los fines específicos del análisis de admisibilidad -los jueces de la CPI han sostenido, en el marco del artículo 15 del ER, que el análisis deberá estar basado en una comparación entre los casos potenciales de la CPI que surjan de una situación y los casos que las autoridades nacionales están investigando.

El reporte de la CPI del 2 de diciembre de 2014 concluye al respecto:

- Durante el período informado, las autoridades colombianas han dado pasos para priorizar las investigaciones y enjuiciamientos de los más responsables por conductas relevantes para el examen preliminar.

14 Consultar actualidades sobre el tema en [https://www.fiscalia.gov.co/colombia/tag/falsos-positivos/]. 
- Las autoridades colombianas hicieron avances en la investigación de los casos de "falsos positivos" pertinentes a los efectos del examen preliminar. Sin embargo, la Fiscalía observa con preocupación lo limitado de los avances en materia de delitos sexuales, a pesar de que la creación de un grupo de trabajo encargado de investigar casos de violencia de género dentro de la Dirección Nacional de Análisis y Contexto de la Fiscalía colombiana (DINAC) podría significar un desarrollo positivo.

- Durante 2015, la Fiscalía siguió en comunicación con las autoridades colombianas para evaluar si se están realizando procedimientos de manera auténtica contra los más responsables por los crímenes más graves con el fin de llegar a determinaciones en materia de admisibilidad.

- La Fiscalía también continuará con su seguimiento y análisis de la aplicación del Marco Jurídico para la Paz, así como los desarrollos legislativos y de otro tipo relativos a la investigación y enjuiciamiento de los casos de "falsos positivos" como parte de su análisis de los procedimientos nacionales relativos a crímenes de competencia de la Corte.

En diciembre de $2019^{[15]}$ las autoridades colombianas informaron sobre el hallazgo de una fosa en la que se encontrarían los restos de más de 50 personas presentadas ilegítimamente como bajas en combate. Esta es una práctica ilegal conocida en Colombia como "falsos positivos".

La información fue revelada por la JEP-recordemos, una instancia creada para investigar los crímenes cometidos durante el conflicto armado con la guerrilla de las FARC y en la que se juzga a ex guerrilleros, militares, agentes del Estado y civiles involucrados-. Los investigadores de la JEP afirmaron que en el cementerio de Dabeiba -ciudad del departamento de Antioquia, situada a $183 \mathrm{~km}$ Medellín- podrían estar los restos de más de 50 personas víctimas de "falsos positivos" -se trata de hombres entre los 15 y los 56 años, con domicilio en Medellín y entre los que se encontrarían personas en condición de discapacidad.

Durante la presidencia de Álvaro Uribe se promovió un modelo de estímulos a los soldados por bajas de sublevados obtenidas, lo cual se consideró el germen de las ejecuciones de civiles.

A nuestro juicio, ante el dolor que ha sentido Colombia, y al que se enfrentan día a día la población y funcionarios involucrados en este tema, lo único viable es fortalecerse para dejar memoria en los jóvenes. Los jóvenes no conocen la historia de Colombia y hay que dejársela viva para que no la repitan, y por otra parte, lograr unirse como

15 Consultar [https://www.bbc.com/mundo/noticias-america-latina-50797861]. 
país para que no haya repetición y conseguir una reparación real de las víctimas ${ }^{16}$. Entendemos que se puede aprender que las víctimas son las que están más dispuestas a perdonar y repararse y el Estado debe comprometerse con todos los mecanismos para que logren esa reparación.

Actualmente, en Colombia, donde la guerra ha dejado hasta 200.000 desaparecidos, se asoma una verdad dolorosa y reparadora. En febrero de 2020 la JEP, el tribunal de justicia transicional ${ }^{17}$ surgido de los Acuerdos de Paz, volvió a investigar las fosas comunes en el cementerio católico de Dabeiba, donde ha recuperado más de medio centenar de cuerpos de presuntas víctimas de ejecuciones extrajudiciales.

Las ramificaciones de los "falsos positivos" siguen siendo una fuente permanente de conmoción en una sociedad que, sin esquivar la verdad, busca pasar la página de la violencia.

En medio de enormes expectativas, el general en retiro Mario Montoya, comandante del Ejército en algunos de los años en que más casos se presentaron, compareció ante la JEP, en una audiencia a puerta cerrada, y en sus respuestas el militar diluyó la responsabilidad de la cadena de mando, e incluso han pedido que lo excluyan de la jurisdicción.

Montoya rechazó asumir responsabilidades y no mostró arrepentimiento, lo que es la primera condición de la JEP para evitar penas alternativas a la cárcel. A pesar de todo, las versiones voluntarias aportadas por algunos involucrados han detallado las presiones por obtener resultados a cambio de recompensas.

Las montañas y selvas de Colombia están llenas de cadáveres de víctimas enterradas sin sus nombres, son por lo menos 2248 casos de "falsos positivos", de acuerdo con los informes de la Fiscalía, pero representan un porcentaje pequeño del universo de desapariciones forzadas. Hay otros 18 sitios a lo largo y ancho de Colombia donde la JEP presume que se encuentran personas dadas por desaparecidas, víctimas de los diferentes actores armados, bien sea agentes del Estado, guerrillas o paramilitares.

En la zona rural de Dabeiba han identificado cinco puntos donde habría víctimas de las FARC. El caso de los "falsos positivos" y otro por secuestros contra la cúpula de las otrora Fuerzas Armadas Revolucionarias de Colombia son los dos frentes en los que se esperan mayores avances en un año decisivo para la justicia transicional. La labor de la JEP aún no ha concluido en Dabeiba, habrá nuevas jornadas.

16 Rodrigo Uprimny. "Los retos jurídicos de la desaparición forzada: de la lucha por el reconocimiento a la lucha por la eficacia de un crimen atroz", en Razones y emociones, disponible en [http://www. dos-mundos.org/pdf/revista/sinras 018.pdf].

17 Consultar [http://www.justiciatransicional.gov.co/]. 


\section{EL PROCESO DE JUSTICIA TRANSICIONAL COMO PARTE INTEGRAL DE LA IMPLEMENTACIÓN DEL ACUERDO DE PAZ EN COLOMBIA}

Para empezar este apartado conviene definir la justicia transicional ${ }^{18}$ : empezó por ser una expresión descriptiva, que fue acuñada en la década de 1990 por varios académicos estadounidenses, para aludir a las diferentes maneras que tenían los países de resolver los problemas presentados cuando un gobierno llegaba al poder después de que sus antecesores cometieran masivas violaciones de derechos humanos.

Esta definición no daba a entender que hubiera un enfoque normalizado y ni siquiera principios comunes, como se desprende de la enorme variedad de métodos que los diferentes países decidían aplicar o no al afrontar esos abusos.

Al principio, la expresión describía diferentes enfoques en distintos lugares, no un concepto o una práctica coherente. En las décadas de 1990 y 2000 surgieron nuevos enfoques y prácticas, basados en el reconocimiento de principios relacionados con los derechos humanos y en que bajo ningún concepto podía ignorarse la vulneración de estos. A todo ello se relacionaban mecanismos como los procesos judiciales, las investigaciones (o iniciativas de "esclarecimiento de la verdad"), los programas de reparación y las propuestas de reforma, que se consideraban los más eficaces para materializar ese respeto a los derechos humanos. Se insiste en cuatro tipos de enfoques que no deben considerarse mutuamente excluyentes:

- Procesos penales, por lo menos contra los principales responsables de los crímenes más graves.

- Procesos de "esclarecimiento de la verdad" (o investigaciones) sobre las violaciones de derechos por parte de órganos no judiciales. Son iniciativas diversas, pero suelen centrarse no sólo en los acontecimientos, sino en sus causas y consecuencias.

- Reparaciones de diversas formas -individuales, colectivas, materiales y simbólicas- en caso de violaciones de derechos humanos.

- Reformas jurídicas e institucionales que pueden afectar a la policía, la justicia, el ejército y los servicios de información militar.

Por ejemplo, las comisiones de la verdad no sustituyen a los procesos judiciales, una vez que sus objetivos son distintos pues ofrecen un grado de reconocimiento mayor y combaten la cultura de la negación. Igualmente, las reformas constitucionales, jurídicas e institucionales no excluyen otras medidas, sino que apuntan directamente a la recuperación de la confianza y a la prevención de nuevos abusos.

18 Consultar [https://www.ictj.org/es/que-es-la-justicia-transicional]. 
Las comisiones de la verdad y de investigación abordan ahora la corrupción de regímenes anteriores con métodos no utilizados por organismos similares hace veinte años. En ciertas circunstancias, las comisiones de la verdad y las reformas legales posibilitan avances importantes en la lucha contra problemas de marginación graves, como es el caso de Sierra Leona, donde las iniciativas de reforma legal mejoraron sustancialmente la situación jurídica de las mujeres a comienzos de la década de 2000.

En el sur de Yemen, la reaparición de la violencia frenó en seco un imaginativo proyecto, centrado en la expropiación masiva de tierras y otras propiedades, pero éste indica que los procesos de justicia transicional pueden en ocasiones llegar incluso a enfrentarse a complejos problemas de tenencia de tierras.

Actualmente, la práctica de la justicia transicional constituye un intento de plantarle cara a la impunidad, aplicar reparaciones eficaces y evitar la repetición de crímenes, a través de una cuidadosa y patente evaluación de los contextos en los que hay que actuar.

En este proceso de paz, la justicia transicional es de importancia crítica, no solo como un instrumento de reparación, sino también como un medio para lograr un proceso de rendición de cuentas, seguridad y estabilidad.

Durante el proceso de paz, la Fiscalía de la CPI ha procurado transmitir mensajes claros a las autoridades colombianas sobre aspectos de la justicia transicional y su coherencia o compatibilidad con el ER, esperando que sus puntos de vista pudiesen asistir a las autoridades colombianas en aspectos importantes del sistema de justicia transicional que estaban diseñando como parte de la paz. La Fiscalía ha procurado explicar cuáles son sus responsabilidades con arreglo al ER, y lo que estas responsabilidades se le exigen (si ha de cumplir el mandato que los Estados Partes del Estatuto, incluida Colombia, le han confiado $)^{19}$.

Los Estados Partes del Estatuto han asumido la responsabilidad primaria de reprimir los crímenes internacionales, como los crímenes de guerra y los crímenes de lesa humanidad, y la CPI solamente es un mecanismo de salvaguarda para asegurar el fin de la impunidad por tales crímenes y que se imparta justicia.

Por consiguiente, la Fiscalía tiene el deber de asegurarse de que se está haciendo justicia, ya que si las autoridades nacionales están cumpliendo sus responsabilidades con arreglo al ER, entonces ya no tendrá razón para intervenir.

Los Estados Partes del Estatuto de Roma, como Colombia, comparten los valores consagrados en el ER: la rendición de cuentas, el poner fin a la impunidad por crímenes

19 Janiel David Melamed Visbal. Justicia transicional en Colombia: huellas literarias sobre el fundador de las FARC, Barranquilla, Universidad del Norte, 2019. 
tales como crímenes de guerra y crímenes de lesa humanidad, y la disuasión de la comisión de esos crímenes.

Las medidas de justicia transicional brindan un amplio espectro de posibilidades para asegurar la rendición de cuentas de los responsables por los crímenes más graves.

Con la JEP -el componente de justicia del Sistema Integral de Verdad, Justicia, Reparación y no Repetición-Colombia ha establecido un sistema innovador, complejo y ambicioso, diseñado para asegurar la rendición de cuentas como parte de la implementación del Acuerdo de Paz. Este sistema genera expectativas esperanzadoras, pero también enfrenta muchos desafíos.

La JEP ha comenzado a funcionar, mientras desarrolla su marco jurídico y está recibiendo informes tanto de la sociedad civil como de las instituciones del Estado, y se espera que adopte todavía más decisiones importantes en el futuro inmediato.

La forma en que la JEP trate los casos contra aquellas personas que posiblemente tengan la mayor responsabilidad por los crímenes más graves cometidos en el contexto del conflicto armado será de suma importancia para la capacidad de nutrir una paz sostenible y duradera en Colombia.

Las medidas para alcanzar este objetivo deberán estar alineadas con los objetivos del ER, si es que han de honrar el compromiso de Colombia con arreglo al ER y asegurar que los crímenes más graves no queden sin castigo. El éxito de estas medidas será juzgado por las víctimas del conflicto armado y por la sociedad colombiana en su conjunto.

A nuestro juicio, para que la paz sea sostenible se deberá hacer justicia, pero también se deberá percibir que se ha hecho justicia, mediante un proceso transparente.

La Fiscalía, por su parte, evaluará la eficacia de las medidas de justicia transicional como una función de sus propias responsabilidades con arreglo al ER, siempre reconociendo el amplio alcance de las medidas que la justicia transicional brinda para asegurar la rendición de cuentas. De esta forma, la Fiscalía hará todo lo que esté a su alcance para seguir ejerciendo un papel positivo y constructivo en Colombia, de conformidad con su mandato con arreglo al ER.

Cómo la JEP aborde los procesos vinculados a crímenes del ER obviamente afectará la evaluación de la Fiscalía de la admisibilidad de los casos que surjan de la situación en Colombia ante la CPI.

La Fiscalía ha estado siguiendo los desarrollos luego de la firma del Acuerdo de Paz entre el Gobierno de Colombia y las FARC-EP, incluyendo la adopción de varias medidas legislativas que implementan el sistema de justicia transicional y regulan diferentes aspectos del funcionamiento de la JEP. 
El examen de la Fiscalía sobre el marco legislativo de la JEP reveló algunos aspectos que podrían posiblemente plantear cuestiones respecto de su coherencia o compatibilidad con el ER.

La definición de la responsabilidad del mando ${ }^{20}$, la definición de graves crímenes de guerra y la forma en que se implementarán las penas que conlleven la restricción efectiva de libertades y derechos fueron focos de especial preocupación.

En cuanto a la definición de la responsabilidad del mando, contenida en el Acto Legislativo 01, en opinión de la fiscal, se aparta en algunos aspectos tanto del derecho internacional consuetudinario como del ER.

Por consiguiente, dependiendo de cómo se interprete esta definición en la práctica, su aplicación podría afectar la capacidad de la JEP de llevar a rendir cuentas a aquellos individuos que posiblemente tengan la mayor responsabilidad por crímenes graves.

En opinión de la fiscal, los siguientes cinco requisitos concurrentes de la definición de la responsabilidad del mando contenida en el Acto Legislativo 01 se apartan del derecho internacional consuetudinario y del ER. A saber: la responsabilidad por actos de los subordinados se basa en el control efectivo sobre la conducta de esos subordinados; el crimen fue cometido dentro del área de responsabilidad del superior; que el superior tuviese capacidad legal y material de emitir órdenes, de modificarlas y de hacerlas cumplir; que el superior tuviese la capacidad material y directa de tomar las medidas adecuadas para evitar o reprimir los crímenes; y que el superior tuviese conocimiento actual o actualizable de la comisión de los crímenes.

Por consiguiente, preocupa a la fiscal que el Acto Legislativo 01 contenga lenguaje que podría interpretarse de manera que restrinja el concepto de la responsabilidad del mando en una forma que va en contra del derecho internacional consuetudinario y del ER.

La Fiscalía también tomó en consideración el significado de la participación activa o determinante en los crímenes por parte de personas que no formaban parte de ninguna organización o grupo armado al momento correspondiente. Sobre este último punto, entendemos que, sobre la base de la decisión reciente de la Corte Constitucional, la participación de terceros ante la JEP será voluntaria.

Corresponderá a la Fiscalía General de la Nación investigar y enjuiciar diligentemente a los individuos que hubiesen contribuido a la comisión de delitos en el marco del conflicto.

20 Kai Ambos, Francisco Cortés Rodas y John Zuluaga. Justicia transicional y derecho penal internacional, Bogotá, Siglo del Hombre Editores, 2018. 
La Fiscalía ha transmitido sus puntos de vista sobre estos aspectos de la legislación en un escrito presentado ante la Corte Constitucional, a pedido de ese tribunal, con la esperanza de que sus opiniones ayudasen a la Corte Constitucional a examinar aspectos importantes de la legislación que gobierna la JEP.

En la actualidad, la responsabilidad del superior jerárquico es admitida en derecho internacional penal. En el artículo 86 del Protocolo I se define superior como aquel "que tenga la responsabilidad personal con respeto al autor de las actuaciones en cuestión, porque este último, al ser su subordinado, está bajo su control"21.

\subsection{La aplicación de sanciones que involucren restricciones efectivas de libertades y derechos ${ }^{22}$}

Otro aspecto importante del marco jurídico que regula la JEP es su esquema de sanciones. Este esquema prevé que los individuos responsables por crímenes graves cumplirán de cinco a ocho años de restricciones efectivas de libertades y derechos, si reconocen responsabilidad por sus crímenes y se comprometen a no repetirlos, desde el comienzo del procedimiento ante la JEP.

Aquellos que reconozcan su responsabilidad por los crímenes de manera tardía cumplirán la misma condena en condiciones privativas de libertad ordinarias, mientras que los que no reconozcan su responsabilidad podrían, de ser condenados, recibir penas de prisión de hasta veinte años.

Las sanciones, incluida la forma en que se cumplen, pueden reflejar la autenticidad de la intención de las autoridades de hacer comparecer a los perpetradores ante la justicia. Esta es la razón por la cual, en el informe intermedio ${ }^{23}$, sobre su examen preliminar, la Fiscalía consideró genuinos los procesos nacionales llevados a cabo contra los líderes de las FARC-EP y el Ejército de Liberación Nacional (ELN), que habían sido condenados en ausencia.

Por consiguiente, un aspecto de la evaluación de la Fiscalía será la forma en que la JEP aborde las condenas ya dictadas. Las sanciones penales efectivas podrían ser de distinto tipo, en la medida que cumplan los objetivos apropiados de las penas, de la retribución, rehabilitación, restauración y disuasión ${ }^{24}$, podrían alcanzar estos objetivos a través de

21 Jaimie Allan Williamson. "Reflexiones acerca de la responsabilidad del mando y la responsabilidad penal", RICR, n. ${ }^{\circ} 869,2008,145-165$.

22 Véase [http://www.oas.org/es/cidh/mandato/Basicos/Principiosprl.asp].

23 Véase Reporte intermedio sobre la situación en Colombia, 2012, disponible en [https://www.icc-cpi. int/NR/rdonlyres/3D3055BD-16E2-4C83-BA85-35BCFD2A7922/285202/OTP2012035032COLResumenEjecutivodelReporteIntermed.PDF].

24 Cristian Daniel Hernández Calderón. Los fines de las penas alternativas en los procesos de justicia 
distintos medios, en la medida que reflejen la condena pública de la conducta criminal y el reconocimiento del sufrimiento de las víctimas, y contribuyan a la disuasión.

La Fiscalía ha expresado su posición de que una suspensión de las penas sería manifiestamente inadecuada, puesto que impediría de facto la imposición de un castigo real a individuos con la mayor responsabilidad por la comisión de los crímenes más graves. Sin embargo, la disminución de las penas es concebible en la medida en que la persona condenada satisfaga determinadas condiciones que podrían justificar una sentencia atenuada.

La Fiscalía ha señalado que tales condiciones podrían incluir el reconocimiento de responsabilidad penal, la desmovilización y desarme, las garantías de no repetición, la participación plena en mecanismos para establecer la verdad sobre crímenes graves, y una posible prohibición temporal de participar en los asuntos públicos, entre otras medidas, así como podrían justificar una reducción de la pena que de otro modo resultaría proporcional a la gravedad del crimen y el grado de responsabilidad del perpetrador.

Las penas alternativas o no privativas de libertad, que conlleven restricciones a la libertad, supervisión y obligaciones, también deberán ser compatibles con la intención genuina de llevar a los condenados ante la justicia -la Fiscalía tomará en consideración una serie de factores que incluirán las prácticas habituales de orden nacional en materia de sanciones por crímenes del ER, la proporcionalidad de la pena en relación con la gravedad del delito y el grado de responsabilidad del delincuente, el tipo y grado de restricciones a la libertad, toda circunstancia atenuante, y las razones que el juez que impone la condena haya dado para decidir la pena concreta, entre otras.

Las penas alternativas surgen como una herramienta efectiva para la consecución de los fines de resocialización, y entre ellas cabe desatacar las penas previstas y enunciadas en las Reglas de Tokio $^{25}$.

transicional. El caso colombiano, tesis de grado, Bogotá, Universidad Santo Tomás, [http://repository. usta.edu.co/]; Nathalia Bautista Pizarro (coord.), El significado de la pena en el marco de un proceso de paz. Reflexiones sobre el caso colombiano, Bogotá, Universidad Externado de Colombia, 2017, [http://zis-online.com/dat/artikel/2017_9_1131.pdf].

25 Reglas de Tokio. Reglas mínimas de las Naciones Unidas sobre las medidas no privativas de la libertad, adoptadas por la Asamblea General en su resolución 45/110, del 14 de diciembre de 1990, arts. 8. ${ }^{\circ}$ y 9. : " "sanciones verbales como la amonestación, la reprensión y la advertencia; la libertad condicional; penas privativas de derechos o inhabilitaciones; sanciones económicas y penas en dinero, como multas y multas sobre los ingresos calculados por días; incautación o confiscación; mandamiento de restitución a la víctima o de indemnización; suspensión de la sentencia o condena diferida; régimen de prueba y vigilancia judicial; imposición de servicios a la comunidad; obligación de acudir regularmente a un centro determinado; arresto domiciliario; el trabajo comunitario, las mutas, permisos y centros de transición; la liberación con fines laborales o educativos; distintas formas de libertad condicional; la remisión; el indulto". 
El acuerdo de La Habana ${ }^{26}$ trae otras penas alternativas a la de prisión en el contexto de las negociaciones y de las condiciones especiales de los territorios después de conflicto:

- Participación/Ejecución en programas de reparación efectiva para los campesinos desplazados.

- Participación/Ejecución de programas de protección medioambiental de zonas de reserva y de programas de construcción y reparación de infraestructuras en zonas rurales: escuelas, carreteras, centros de salud, viviendas, centros comunitarios, infraestructuras de municipios, etc.

- Participación/Ejecución de programas de desarrollo rural.

- Participación/Ejecución de programas de eliminación de residuos en las zonas necesitadas de ello.

- Participación/Ejecución de programas de mejora de la electrificación y conectividad en comunicaciones de las zonas agrícolas.

- Participación/Ejecución en programas de sustitución de cultivos de uso ilícito y en programas de recuperación ambiental de las áreas afectadas por cultivos de uso ilícito.

- Participación/Ejecución de programas de construcción y mejora de las infraestructuras viales necesarias para la comercialización de productos agrícolas de zonas de sustitución de cultivos de uso ilícito.

- Participación/Ejecución de programas de construcción y reparación de infraestructuras en zonas urbanas: escuelas, vías públicas, centros de salud, viviendas, centros comunitarios, infraestructuras de municipios, etc.

- Participación/Ejecución de programas de desarrollo urbano.

- Participación/Ejecución de programas de acceso a agua potable y construcción de redes y sistemas de saneamiento.

- Limpieza y erradicación de restos explosivos de guerra, municiones sin explotar y minas antipersonales de las áreas del territorio nacional que hubiesen sido afectadas por estos artefactos.

- Participación/Ejecución de programas de limpieza y erradicación de restos explosivos de guerra y municiones sin explotar.

26 Carlos Arturo Gómez Pavajeau. La justicia transicional en los acuerdos de La Habana y sus especificidades, Bogotá, Universidad Externado de Colombia, 2017. 
- Participación/Ejecución de programas de limpieza y erradicación de minas antipersona y artefactos explosivos improvisados ${ }^{27}$.

Tal y como aparece en los acuerdos, las penas en justicia transicional tienen una vocación eminentemente reparadora y restaurativa de los derechos de las víctimas; debe interesar más la satisfacción a las víctimas, y esto no podría darse en un contexto de retribución, pues lo que se busca es la reconciliación de la sociedad.

Consideramos que en la justicia transicional la pena tiene otros paradigmas, una vez que está en juego no solamente el orden público, sino el sistema mismo, el ordenamiento jurídico, el orden democrático y la paz.

En los sistemas penales de justicia transicional se busca la solución de estados en conflicto y de grave afectación de derechos humanos por eso se utilizan herramientas excepcionales, por el cambio de los acontecimientos en una búsqueda de libertad y garantía de goce de los derechos de los ciudadanos. Si bien el sistema de penas adoptado en los acuerdos no se instituyó la pena efectiva de prisión, si se implementó un sistema de restricción efectivo de la libertad.

En conclusión, la solución y el régimen de penas respetan el régimen penal internacional, la Constitución política y el ordenamiento interno, pues el Estado en su soberanía puede estipular las políticas públicas para llegar a la prevención de los delitos, e impedir la repetición de los hechos que afectaron gravemente los derechos humanos con el propósito de alcanzar un derecho superior como sería la paz.

La Fiscalía ha señalado que la efectividad de tales condenas dependerá de la naturaleza y los alcances de las medidas que, combinadas, conformen la totalidad de la sanción impuesta al delincuente y de si, en las circunstancias concretas de un caso, éstas cumplen de manera adecuada los fines de la pena para los crímenes más graves y brindan reparación a las víctimas.

La reparación para las víctimas dependerá de si las actividades políticas que se permitan a los perpetradores son compatibles con el objeto y fin de las penas impuestas, y de que no las frustren. También será necesaria una rigurosa verificación de la ejecución de las penas por parte de la JEP.

La estrategia y la política de enjuiciamiento de la Fiscalía están diseñadas como una función del carácter global de la CPI y del mandato particular de la Fiscalía. El sistema de la CPI difiere significativamente de los sistemas judiciales nacionales, que operan en circunstancias distintas y con arreglo a regímenes jurídicos diferentes. 
Respecto de la situación en Colombia, la JEP enfrenta una tarea gigantesca, en parte por la importancia de demostrar resultados y de dictar sentencias por los crímenes más graves y más representativos en un futuro cercano. Esto será tranquilizador para el público e importante para la credibilidad del sistema de justicia transicional que se está implementando. La JEP deberá contar con todo el apoyo posible, de todos los actores relevantes en el proceso de paz.

En Colombia, el sistema de justicia transicional enfrenta un vasto universo de crímenes cometidos por muchos perpetradores contra cientos de miles de víctimas. Este universo de crímenes incluye miles de actos de homicidios, secuestros, torturas, violencia de carácter sexual ${ }^{28}$ o basada en consideraciones de género, por mencionar algunas pocas formas de criminalidad, muchos de las cuales constituyen crímenes de la CPI.

La JEP examinará la responsabilidad no solamente de aquellos al nivel jerárquico más elevado que puedan haber ordenado, dirigido o participado de algún otro modo en la comisión de crímenes, ya sea por acción u omisión, sino también a aquellas personas que estén en los eslabones más bajos de la cadena de mando. En tales circunstancias, es claramente imposible prestar atención a todos los casos al mismo tiempo.

Por consiguiente, es necesario definir criterios que sean claros, justificados y proporcionados para la selección y priorización de casos, que en cualquier jurisdicción, puede generar controversias, debido a que no todos los delitos serán abordados inmediatamente. Por esta razón, es importante establecer un proceso basado en consideraciones jurídicas y estratégicas claras, y una metodología que se aplique en forma consistente a los casos contra diferentes grupos de perpetradores, de manera equitativa.

De este modo, no solo se hace justicia, sino que también se percibe que se está haciendo justicia, y el público entenderá y apoyará el proceso.

La Fiscalía es el órgano encargado de seleccionar entre las numerosas situaciones y casos abarcados por la competencia de la Corte. Por consiguiente, la Fiscalía sigue directrices claras y transparentes a los efectos de ejercer su discrecionalidad para perseguir penalmente a través de la selección y priorización de los casos que presentará ante los jueces de la CPI.

La política de la Fiscalía surge de la realidad práctica de un tribunal con alcance internacional que ejerce su competencia sobre múltiples situaciones en forma simultánea, pero con recursos limitados.

28 Elisabeth Wood. "La violencia sexual en el marco de conflictos armados: hacia un entendimiento de su variación”, en Análisis Político, vol. 22, n. ${ }^{\circ}$ 66, Bogotá, mayo/agosto de 2009. 
Hemos señalado que el principio de jurisdicciones complementarias significa que la CPI solamente actuará allí donde los Estados Partes no puedan realmente llevar a cabo su responsabilidad primaria de investigar y enjuiciar los crímenes del ER.

Sin embargo, una vez que la Fiscalía ha iniciado una investigación de una situación, seleccionará y priorizará casos específicos para su investigación y posible enjuiciamiento dentro de esa situación, sobre la base de una serie de consideraciones jurídicas, fácticas y estratégicas.

De este modo, la Fiscalía distingue entre "situaciones" y "casos": las "situaciones" se definen en términos de parámetros temporales, territoriales y, en algunos casos, personales; los “casos" se definen en términos de incidentes concretos dentro de una determinada situación que conllevan la comisión de uno o más crímenes.

La CPI no puede hacer todo al mismo tiempo, por eso la Fiscalía centra sus esfuerzos en casos relacionados con aquellas personas que parezcan ser las más responsables por crímenes que son particularmente graves, o que han tenido un impacto muy significativo, tomando en consideración la gravedad de incidentes concretos quizá como el factor más importante para la selección de casos para su investigación y enjuiciamiento. El factor de la gravedad abarca tanto consideraciones cuantitativas como cualitativas, como la escala, la naturaleza, la forma de comisión y el impacto de los crímenes. También toma en consideración el grado de responsabilidad de los presuntos perpetradores y la naturaleza de los cargos posibles.

Al seleccionar los casos, la Fiscalía también procura representar, en la medida de lo posible, el verdadero alcance de la criminalidad que se ha producido en una situación concreta. En este marco, procura identificar los cargos que mejor reflejan los principales tipos de victimización y las principales comunidades afectadas por los crímenes ${ }^{29}$.

La Fiscalía alienta de manera sostenida las investigaciones nacionales de presuntos crímenes que no satisfacen los criterios para su enjuiciamiento ante la CPI. En particular, procura cooperar con los Estados y la comunidad internacional para asegurar

29 La Sala de Reconocimiento estableció los criterios de selección y de priorización, así la JEP no podrá investigar todos los casos, y debe seleccionar los más graves y representativos. Los casos que se han abierto hasta la fecha son: Caso 001 (abierto el 6 de julio de 2018): Retención ilegal de personas por parte de las Farc-EP. Caso 002 (abierto el 10 de julio de 2018): Prioriza la grave situación de derechos humanos padecida por la población de los municipios de Tumaco, Ricaurte y Barbacoas (Nariño). Caso 003 (abierto el 17 de julio de 2018): Sobre muertes ilegítimamente presentadas como bajas en combate por agentes del Estado. Caso 004 (abierto el 11 de septiembre de 2018): Prioriza la situación humanitaria de los municipios de Turbo, Apartadó, Carepa, Chigorodó, Mutatá, Dabeiba (Antioquia), El Carmen del Darién, Riosucio, Unguía y Acandí (Chocó). Caso 005 (abierto el 8 de noviembre de 2018): Prioriza la situación humanitaria de los municipios de Santander de Quilichao, Suárez, Buenos Aires, Morales, Caloto, Corinto, Toribío y Caldono (Cauca), disponible en [https:// www.jep.gov.co/Infografas/brochure.pdf]. 
que se empleen todos los medios adecuados para llevar a otros perpetradores ante la justicia. Luego de hacer una selección de los casos, la Fiscalía los prioriza dentro de una determinada situación, e incluso entre distintas situaciones.

Esto permite asegurar una gestión adecuada de la carga general de trabajo, habitualmente dentro de un plazo razonable, de conformidad con los recursos que la Fiscalía tiene a disposición para ello, así como también otras limitaciones prácticas, como la situación de seguridad en el terreno. De este modo se procura llevar adelante, en el tiempo, casos que cumplan los criterios de selección -un caso que no es priorizado no se cierra, permanece como parte del grupo de casos identificados para la investigación por la CPI, cuando las circunstancias lo permitan.

\subsection{El papel de la CPI en un proceso de justicia transicional ${ }^{30}$}

El concepto de justicia transicional abarca una gran cantidad de procesos que las sociedades emplean para enfrentar el legado de los abusos a los derechos humanos del pasado, y lograr un proceso de rendición de cuentas, justicia y reconciliación.

Para cumplir estos objetivos, la justicia transicional habitualmente recurre a cuatro medidas, el Acuerdo de Paz en Colombia adopta estas y otras medidas, en el marco de un único sistema de justicia transicional:

- juicios penales, mecanismos para el establecimiento de la verdad;

- programas de reparaciones;

- garantías de no repetición (podrá haber también otras medidas).

La justicia transicional no es un tipo especial de justicia, sino simplemente un enfoque para obtener justicia en un período de transición de un conflicto armado, por ejemplo, o una condición de opresión estatal.

El mandato de la CPI se relaciona principalmente al componente de justicia penal de este sistema, esto no significa que los otros aspectos de un sistema de justicia transicional, como las comisiones de la verdad o las reparaciones, resulten irrelevantes para la CPI, sino que significa simplemente que estos mecanismos no constituyen el foco de atención principal de la Fiscalía en su análisis respecto de si un caso es admisible ante la CPI.

Una situación de justicia transicional sólo activa el mandato de la Fiscalía de la CPI si las autoridades del Estado en cuestión no están realmente llevando a cabo procesos por tales crímenes bajo el ER. 
Primeramente, para analizar si las autoridades nacionales están realmente llevando a cabo procesos nacionales, la Fiscalía toma en consideración si el Estado ha iniciado procesos en relación a casos potenciales que podrían ser investigados por la Fiscalía $\mathrm{y}$, de ser ese el caso, si esos procesos son genuinos.

En el contexto de la justicia transicional, este análisis deberá ser holístico: los aspectos de justicia penal del sistema podrán ser considerados en el contex to más amplio de otros mecanismos relevantes de justicia transicional.

Sin embargo, si no parece que el Estado haya iniciado procesos en relación con casos que podrían ser objeto de investigación por parte de la CPI, o que los procesos que se han iniciado no son genuinos, sino que solo buscan sustraer a los perpetradores de la responsabilidad penal, entonces la Fiscalía intervendría para cumplir uno de los componentes de la justicia transicional: las investigaciones y los enjuiciamientos penales.

Por procesos, por supuesto, el ER hace referencia a procesos penales en el sentido tradicional, esto es, procesos que involucran un enjuiciamiento penal, una decisión acerca de la culpabilidad o inocencia de la persona imputada y, en caso de condena, la imposición de una sanción penal.

Los procesos de naturaleza no penal, como los procesos para establecer reparaciones para las víctimas, podrían ser tomados en consideración a los efectos de analizar la seriedad de los esfuerzos nacionales, en el contexto de una evaluación holística, pero en sí mismos no tornarían un caso inadmisible ante la CPI.

\subsubsection{Amnistía y su relación con las medidas de justicia de transición}

Se designan con la palabra amnistía ${ }^{31}$ las medidas jurídicas que tienen como efecto: la posibilidad de impedir el enjuiciamiento penal y, en algunos casos, las acciones civiles contra ciertas personas o categorías de personas con respecto a una conducta criminal específica cometida antes de la aprobación de la amnistía; o la anulación retrospectiva de la responsabilidad jurídica anteriormente determinada.

Las amnistías no impiden que se haga efectiva la responsabilidad jurídica respecto de una conducta que todavía no ha tenido lugar, que constituiría una invitación a violar la ley. La amnistía tal como se ha definido es distinta de un indulto, que se utiliza para indicar un acto oficial que exime a un delincuente o delincuentes condenados de la aplicación de la pena en todo o en parte, sin borrar la condena en que se basa.

31 La palabra amnistía deriva de la palabra griega amnestia, que es también la raíz de amnesia. La raíz griega connota el olvido más bien que el perdón de un crimen que ya ha sido objeto de una condena penal. Véase Diane Orentlicher. "Settling accounts: the duty to prosecute human rights violations of a prior regime”, en Yale Law Journal, vol. 100, n. . 8 (1991), 2537. 
En la práctica los Estados han utilizado muy diversas expresiones -incluidos el indulto y la clemencia- para indicar leyes que corresponden a la definición de amnistía ${ }^{32}$.

Las amnistías son distintas además de las diversas formas de inmunidad oficial en derecho internacional, como las inmunidades de los jefes de Estado y las diplomáticas, que protegen a los funcionarios del ejercicio de la jurisdicción de un Estado extranjero pero no deben inmunizarlos, en la medida y durante el período en que ellas sean aplicables.

La Fiscalía ha afirmado en varias ocasiones que no emite opinión respecto de las amnistías por los llamados "delitos políticos", como la rebelión, la sedición o la traición, puesto que tales crímenes no están abarcados por la competencia de la CPI, que abarca el genocidio, los crímenes de lesa humanidad, los crímenes de guerra y, el más recientemente, el crimen de agresión. Sin duda, una amnistía por conductas que constituyeran crímenes del ER plantearía cuestiones muy distintas; pero, por otra parte, una amnistía por crímenes que no están abarcados por el ER no es una cuestión que competa a la Fiscalía de la CPI.

Respecto de los crímenes potencialmente abarcados por la competencia de la CPI, la Fiscalía ha observado con optimismo que la decisión de la Corte Constitucional de Colombia en cuanto a la aplicación de la Ley de Amnistía ajustó las disposiciones relativas a amnistías, indultos y al beneficio especial de renuncia de la persecución penal por crímenes de guerra.

Si bien el texto original de la Ley de Amnistía había excluido las amnistías, los indultos y las renuncias a la persecución penal solamente respecto de los graves crímenes de guerra, definidos como toda infracción al derecho internacional humanitario cometida de forma sistemática, la Corte Constitucional, según el comunicado que emitió, decidió que estos beneficios no podían otorgarse a individuos respecto de ningún crimen de guerra -cometido de forma sistemática o no.

La Corte Constitucional indicó que definir la expresión graves crímenes de guerra como violaciones al derecho internacional humanitario cometidas en forma sistemática no era aplicable, puesto que la sistematicidad no es un elemento exigido para que una conducta constituya un crimen de guerra con arreglo al derecho penal internacional.

Esta posición apoya, incidentalmente, la postura de la Fiscalía; también es compatible con el deber de los Estados de investigar y enjuiciar los crímenes más graves, entre ellos los crímenes de guerra, como principio establecido del derecho internacional.

32 Véase, por ejemplo, Comisión Africana sobre Derechos Humanos y de los Pueblos, Zimbabwe Human Rights NGO Forum c. Zimbabwe, comunicación n. ${ }^{\circ}$ 245/2002, párr. 196 ("Se puede ser indultado incluso antes de ser acusado o condenado oficialmente"). 
La verdad, la justicia y las reparaciones son respuestas complementarias, más que alternativas, a las violaciones manifiestas de derechos humanos y las violaciones graves del derecho internacional humanitario. Si bien en algunos casos la revelación completa de la verdad acerca de las violaciones puede justificar una reducción de la sentencia de una persona, las medidas de la justicia de transición, como el establecimiento y el funcionamiento de comisiones de la verdad, no deben exonerar a los autores de un juicio penal a cambio de su testimonio. Así mismo, la reparación otorgada a las víctimas por las violaciones de derechos humanos y del derecho internacional humanitario no reduce la obligación de los Estados de velar por el enjuiciamiento de los crímenes de guerra y de las violaciones graves de los derechos humanos.

Una de las comisiones de la verdad más conocidas y ampliamente respetadas -la Comisión de la Verdad y la Reconciliación de Sudáfrica- estuvo facultada en ciertas circunstancias para conceder amnistía a los autores que revelaran plenamente la verdad acerca de los crímenes de la era del Apartheid, algunos comentaristas consideran que es posible renunciar a los enjuiciamientos incluso respecto de crímenes atroces si al hacerlo se facilita la plena revelación de la verdad.

Pero aunque la amnistía de Sudáfrica no se puso a prueba en un órgano internacional de derechos humanos, se duda de que hubiera sobrevivido el escrutinio de acuerdo con las normas jurídicas elaboradas por órganos como el Comité de Derechos Humanos, la Comisión Interamericana y la Corte Interamericana de Derechos Humanos ${ }^{33}$, que han indicado que las amnistías son incompatibles con las obligaciones de los Estados de conformidad con los tratados pertinentes incluso cuando el Estado de que se trate haya creado una comisión de la verdad y otorgado reparación a las víctimas.

En Colombia, en el marco del Acuerdo Final para la terminación del conflicto y la construcción de una paz estable y duradera, suscrito entre el Gobierno de Colombia y las Fuerzas Armadas Revolucionarias de Colombia-Ejército del Pueblo (FARC-EP), mediante el Acto Legislativo 01 de 2017 y el Decreto 588 de 2017, se creó la Comisión para el Esclarecimiento de la Verdad, la Convivencia y la No Repetición, como un mecanismo de carácter temporal y extrajudicial del Sistema Integral de Verdad, Justicia, Reparación y No Repetición (SIVJRNR), para conocer la verdad de lo ocurrido en el marco del conflicto armado y contribuir al esclarecimiento de las violaciones e infracciones cometidas durante el mismo y ofrecer una explicación amplia de su complejidad a toda la sociedad.

33 Véase Sherrie Russell-Brown. "Out of the crooked timber of humanity: the conflict between South Africa's Truth and Reconciliation Commission and international human rights norms regarding 'effective remedies", , en Hastings International and Comparative Law Review, vol. 26, n. 2 (2003), 227. Se litigó con respecto a la amnistía sudafricana ante el Tribunal Constitucional de Sudáfrica, que reafirmó la validez de la amnistía tanto en derecho interno como en derecho internacional. Sin embargo, se ha criticado ampliamente el trato que dio el Tribunal sudafricano a la normativa pertinente de derecho internacional. 
El SIVJRNR está compuesto por los siguientes mecanismos y medidas: la JEP, la Comisión para el Esclarecimiento de la Verdad, la Convivencia y la No Repetición; la Unidad para la Búsqueda de Personas dadas por Desaparecidas en el contexto y en razón del conflicto armado; las medidas de reparación integral para la construcción de paz y las garantías de no repetición; y requiere ser integral, para que las medidas logren un máximo de justicia y de rendición de cuentas sobre las violaciones de los derechos humanos e infracciones al derecho internacional humanitario (DIH) ${ }^{34}$ ocurridas a lo largo del conflicto.

Los mecanismos y medidas de verdad, justicia, reparación y no repetición, en tanto parte de un sistema que busca una respuesta integral a las víctimas, no pueden entenderse de manera aislada, una vez que están interconectados a través de relaciones de condicionalidad y de incentivos para acceder y mantener cualquier tratamiento especial de justicia, siempre fundados en el reconocimiento de la verdad y de las responsabilidades.

¿Es lícita una amnistía o un proyecto de amnistía? ¿Tiene el efecto jurídico de impedir los juicios penales, los recursos civiles, o ambos? Algunas disposiciones jurídicas son claramente amnistías tal como se definen en este instrumento aunque se usen formulaciones distintas de "se otorga amnistía".

Colombia surge como ejemplo de disposición más ambigua: con la Ley de Justicia y Paz de Colombia - Ley 975 (del 21 de junio de 2005) se ofrece beneficios principalmente en forma de sentencias reducidas a los miembros de las organizaciones paramilitares que se desmovilicen, se desarmen y suministren información o colaboren en el desmantelamiento del grupo al que pertenecían.

No siempre es claro si una amnistía excluye de su ámbito de aplicación todos los delitos que se deben excluir de conformidad con el derecho internacional y la política de las Naciones Unidas. Las expresiones pueden enmascarar el funcionamiento de una amnistía impermisible ${ }^{35}$.

A cambio de cumplir esos requisitos, los beneficiarios pueden recibir penas más reducidas que las penas que el tribunal competente determine que son apropiadas antes de aplicar los beneficios de sentencia de la Ley de Justicia y Paz, que consiste en "privación de libertad" por un período de por lo menos cinco años, pero no superior a ocho años, período que se determina exactamente "de acuerdo con la gravedad de los delitos y su colaboración efectiva en el esclarecimiento de los mismos" (art. 29).

34 Jorge Giraldo Ramírez. La tercera realidad: Escritos sobre paz, reconciliación y derecho humanitario, Sílaba Editores, 2016.

35 Louise Mallinder. Amnesty, Human Rights and Political Transitions: Bridging the Peace and Justice Divide, Oxford, Hart Publishing, 2008, 30. 
Si bien ofrece penas reducidas a quienes reúnan las condiciones, la Ley de Justicia y Paz no los exime del juicio penal, crea una Unidad Nacional de Fiscalías de Justicia y Paz con la función de investigar los actos delictivos cometidos por los solicitantes, comprobar la veracidad de la información suministrada y aclarar esos hechos y todos aquellos de los cuales tenga conocimiento dentro del ámbito de su competencia (arts. 16 a 18). Por cuanto la ley no extingue completamente la responsabilidad penal respecto de los beneficiarios, no es una amnistía.

Sin embargo, esto no aclara las preocupaciones en cuanto a si es plenamente compatible con las obligaciones internacionales de Colombia de velar por que los autores de delitos de derechos humanos sean enjuiciados en los juicios penales correspondientes, que se realice plenamente el derecho de las víctimas y la sociedad a la verdad, y que se otorguen a las víctimas recurso y reparación efectivos ${ }^{36}$.

En mayo de 2007 la Corte Interamericana de Derechos Humanos dio orientación acerca de la forma en que debería aplicarse la Ley de Justicia y Paz para ser compatible con la Convención Americana sobre Derechos Humanos: la Corte determinó que "las disposiciones que impidan la investigación y el castigo de los responsables de violaciones graves son inadmisibles"; "la pena que el Estado asigne a los autores de conducta ilícita debe ser proporcional a los derechos reconocidos por la ley y la culpabilidad con que hayan actuado los autores, lo que a su vez se debe determinar cómo función de la naturaleza y la gravedad de los hechos. La pena debe ser el resultado de un fallo dictado por una autoridad judicial"37.

Además de los mecanismos judiciales, las violaciones manifiestas de los derechos humanos se pueden abordar aplicando medidas de justicia de transición más amplias.

En la Declaración de la Reunión de Alto Nivel sobre el Estado de Derecho, los Estados Miembros destacaron la importancia de un enfoque global de la justicia de transición que abarcase medidas judiciales y no judiciales dirigidas a garantizar la rendición de cuentas, hacer justicia, ofrecer vías de recurso a las víctimas, fomentar la cicatrización de las heridas y la reconciliación, establecer entidades independientes que supervisasen los sistemas de seguridad, restablecer la confianza en las instituciones del Estado y promover el Estado de derecho.

Observaron que esos enfoques, que incluyen procesos de búsqueda de la verdad, entre ellos los que investigan los tipos de violaciones anteriores de las normas internacionales

36 En un fallo del 18 de mayo de 2006 el Tribunal Constitucional de Colombia declaró que varias disposiciones de la ley eran inconstitucionales y enmendó efectivamente otras de manera de compatibilizar la ley con las obligaciones internacionales y constitucionales de Colombia.

37 Caso de la Masacre de la Rochela c. Colombia, fallo del 11 de mayo de 2007, serie C, n. ${ }^{\circ} 163$, párrs. 194 y 196. 
de derechos humanos y el DIH, así como sus causas y consecuencias, son herramientas importantes que pueden servir de complemento a los procesos judiciales.

No es fácil definir qué tipo o grado de participación hace que una medida de justicia transicional sea considerada legítima, por lo tanto, existen tres objetivos que puede perseguir la participación, que plantean requisitos distintos para que esta pueda ser considerada fuente de legitimidad de las medidas de justicia transicional: la expresión de puntos de vista, la incidencia y la transformación de las relaciones de poder. Cada uno de esos objetivos tiene fortalezas y debilidades relacionadas con los requisitos que impone y las posibilidades que existen para su satisfacción.

No obstante, no siempre la adopción de las medidas de justicia transicional se da como resultado de esfuerzos activos de promoción por parte de las víctimas o de la sociedad civil. En muchos contextos, en especial en años recientes debido al auge de la justicia transicional en el discurso internacional de los derechos humanos, tales medidas son promovidas por las élites políticas en virtud de la presión internacional o de la necesidad de legitimación interna. En estos casos la promoción de la justicia transicional no constituye un escenario de participación y, además, es difícil que haya una participación robusta y eficaz en la adopción e implementación de las medidas de justicia transicional, debido a la falta de movilización política y de organización previas por parte de las víctimas y la sociedad civil.

La participación de las víctimas y la sociedad civil en el desarrollo de medidas de justicia transicional puede comenzar mucho antes de la adopción oficial de tales medidas, e incluso antes de la transición política de la guerra a la paz o de la dictadura a la democracia, cuando dichos sectores se movilizan contra la impunidad y exigen que se establezcan medidas de justicia, verdad, reparación y garantías de no repetición.

El caso colombiano ofrece un buen ejemplo de cómo la combinación de la promoción de la justicia transicional desde abajo, con la promoción oficial de la participación puede incrementar el impacto de la participación de las víctimas y de la sociedad civil.

En Colombia ${ }^{38}$, en la última década, las víctimas y las organizaciones de derechos humanos pasaron de ser sectores marginados y perseguidos a ser actores políticos cada vez más organizados y con mayor capacidad de expresión de sus puntos de vista y de incidencia en la arena nacional. Esta transformación ha sido el resultado de su activa lucha contra la impunidad, pero también de los mecanismos que en pos de su participación se han establecido en respuesta a sus demandas.

38 Gustavo Emilio Cote Barco, Catalina Ibáñez Gutiérrez, Nelson Camilo Sánchez, Diego Fernando Tarapués Sandino, Gonzalo Villa Rosas y John E. Zuluaga. Justicia de Transición y Constitución I: análisis de la sentencia C-579 de 2013 de la Corte Constitucional, vol. 1, Bogotá, Temis, 2014. 
La lucha contra la impunidad de esas organizaciones es de larga data, pero su articulación como estrategia política nacional de promoción de la justicia transicional se concretó a comienzos del siglo XXI, con motivo de la desmovilización de los grupos paramilitares de derecha.

En el 2005, el Gobierno colombiano impulsó una ley que contemplaba procesos penales especiales de reducción sustancial de penas por confesión de crímenes atroces (Ley 975 de 2005, o Ley de Justicia y Paz). La ley estuvo precedida de proyectos que solo proponían mecanismos no punitivos de justicia, y la oposición de las organizaciones de la sociedad civil condujo a que se desechara la solución no penal.

Sin embargo, los procesos penales que se concibieron permitían un alto grado de impunidad en la práctica, pues solo aplicaban a los perpetradores que ya tuvieran procesos judiciales abiertos en su contra, y no preveían mecanismos para garantizar los derechos de las víctimas.

Las organizaciones de víctimas y de la sociedad civil lanzaron una estrategia de movilización jurídica ante las altas cortes del país, que condujo a que varios apartes de la ley y de sus desarrollos posteriores fuesen declarados inconstitucionales o condicionados con el fin de reducir el riesgo de impunidad, así como de fortalecer la participación de las víctimas en los juicios y de garantizarles sus derechos a conocer la verdad y a recibir reparaciones judiciales adecuadas.

A través de sus denuncias permanentes y de su acción decidida frente a la Fiscalía, el ministerio público y los jueces encargados de la aplicación de la ley, esas organizaciones han insistido en que esta sea favorable a los derechos de las víctimas en su aplicación, lo cual también ha contribuido a ampliar las medidas de justicia y la participación de las víctimas en ella. La movilización política y jurídica de las víctimas por la justicia transicional condujo a que sus derechos se convirtieran en un tema central de la agenda política nacional, y también a que su participación en el debate de ese tema fuese considerada cada vez más necesaria.

En efecto, en el año 2010, el Gobierno colombiano propuso ante el Congreso de la República una ley de reparación para las víctimas del conflicto armado, que tiene como antecedente una iniciativa presentada por el Partido Liberal en 2007 y preparada en conjunto con organizaciones sociales. La Ley 1448, conocida como Ley de Víctimas, fue aprobada en el 2011, tras varios debates y foros de discusión con amplia participación de organizaciones de víctimas y de la sociedad civil. Entre otras cosas, el Congreso de la República realizó audiencias regionales para escuchar la opinión de las víctimas sobre la propuesta legislativa.

Como resultado de la deliberación, la Ley de Víctimas contempla no solo un amplio menú de medidas de restitución y reparación -material, colectiva y simbólica- sino también un novedoso mecanismo de participación de las víctimas en su implementación. 
La ley creó mesas de participación de víctimas, no solo en el nivel nacional, sino también en los niveles departamental y municipal, para que todas las decisiones referidas a la aplicación de la ley fueran discutidas y monitoreadas por representantes elegidos por las víctimas. Las víctimas y la sociedad civil obtuvieron un rol político aún más protagónico con motivo de las negociaciones de paz que adelantaron el Gobierno colombiano y el principal grupo guerrillero del país (las FARC-EP) entre los años 2012 y 2016 en Cuba. Aunque promovidas por representantes de cada parte del conflicto, desde el comienzo las negociaciones reconocieron la centralidad de los derechos de las víctimas, así como la importancia de la participación de la sociedad en general y de las víctimas en particular en la construcción e implementación de la paz.

Las partes definieron los derechos de las víctimas como uno de los seis temas centrales para ser negociados. Además, incluyeron la participación como objetivo orientador del procedimiento de las negociaciones en el acuerdo base de estas.

El caso colombiano ilustra la manera como los procesos organizativos de las víctimas logran que incrementalmente ellas y sus organizaciones sean tenidas en cuenta en escenarios de deliberación política cada vez más determinantes.

Así, si en un principio las víctimas lograron tener incidencia en la política pública de reparaciones, posteriormente, con la instalación de la mesa de negociaciones entre el Gobierno y las FARC, y gracias al acumulado organizativo, las víctimas lograron posicionar la idea de que los diálogos de paz no podían ser emprendidos sin su participación.

Dentro del proceso de paz, también de manera incremental, se fueron ganando espacios de participación cada vez más directos. Si ya era novedoso que las partes negociadoras abrieran la posibilidad de que les enviaran propuestas escritas y de que se instalaran foros para recoger observaciones a los temas de negociación, el que representantes de diversos sectores de víctimas fueran invitados a dialogar con las partes negociadoras fue un logro enorme.

Ahora bien: ninguno de esos procesos de participación ha estado exento de críticas.

La deliberación de la Ley de Víctimas adoleció, según muchas organizaciones, de la amplitud necesaria para incluir los puntos de vista de las diferentes organizaciones, en especial aquellas con menos niveles de organización y recursos, y ubicadas fuera de la capital del país. Además, los foros regionales promovidos por el Congreso fueron cuestionados como espacios para hacer proselitismo electoral, a los cuales las víctimas fueron convocadas no para participar en el diseño de la propuesta sino para realizar observaciones sobre una propuesta diseñada en la capital, observaciones que luego no fueron tenidas en cuenta.

En cuanto a los ámbitos de participación creados por las negociaciones de paz, las mayores críticas se refirieron a la falta de representatividad de las personas seleccionadas 
para participar en los foros y para dialogar con los negociadores de paz, así como a la tardanza de las partes en abrir un espacio de participación para los grupos étnicos, que insistieron en su importancia desde el comienzo del proceso.

Sea como fuere, los espacios oficiales creados para la participación de las víctimas en Colombia han reconocido la importancia que estas se forjaron en la arena política. Este reconocimiento ha conducido al empoderamiento político de las víctimas, que se manifiesta no solo en su intervención cada vez más frecuente en los escenarios de discusión y en su visibilidad en los medios de comunicación, sino también en su capacidad de promover o apoyar la movilización social por causas más amplias que las propias.

Las experiencias estudiadas muestran que el proceso de adopción de las medidas de justicia transicional ofrece distintos escenarios democráticos que, en mayor o menor medida, permiten a las víctimas y a la sociedad en su conjunto ser partícipes e intentar moldear las decisiones fundamentales sobre la manera como debería ser enfrentado el periodo de abusos o atrocidades que se pretende superar a través de la transición.

Existen al menos tres tipos de escenarios que permiten la participación en el proceso de adopción de las medidas de justicia transicional: los espacios deliberativos durante la discusión política, la consulta previa de las medidas que se van a adoptar y la refrendación posterior de esas medidas.

En orden ascendente, cada uno de esos escenarios permite, en un nivel mayor, que las preferencias de los participantes impacten el contenido definitivo de las medidas de justicia transicional, al tener un nivel más vinculante para los Estados en la toma de decisiones.

Los escenarios de participación en la adopción de medidas de justicia transicional son: deliberación, consulta, ratificación. Cada uno de los escenarios de participación en la adopción de medidas de justicia transicional responde a propósitos distintos, todos ellos importantes. Por esa razón, parece deseable que, en la medida de lo posible, tales escenarios no sean excluyentes sino complementarios entre sí, de modo que aumenten las potencialidades de la participación que cada uno promueve.

Los escenarios permiten la participación de las víctimas, no solo como población "objeto" de las medidas, sino también como sujetos activos en el proceso de implementación. Igualmente, ofrecen oportunidades para que la sociedad civil participe en dicho proceso.

Los escenarios que identificamos como participativos son variados e incluyen tanto espacios cuyo objetivo principal y directo es garantizar la participación de las víctimas y la sociedad civil -como las audiencias y otros escenarios en los cuales las víctimas pueden presentar sus testimonios-, cuanto aquellos que tienen un objetivo 
distinto al participativo pero que también abren la posibilidad de que las víctimas y la sociedad civil se involucren -como la composición de los órganos encargados de implementar las medidas, o los espacios de información y difusión para medios de comunicación.

Igualmente, los espacios participativos que identificamos incluyen no solo aquellos oficiales o abiertos por el Estado, sino también algunos extraoficiales, que son abiertos por las víctimas con el objetivo de complementar o de ofrecer alternativas a los oficiales.

El ejemplo típico de consulta previa es aquella prevista por el Convenio 169 de la Organización Internacional del Trabajo (OIT), que exige que esta tenga lugar siempre que se tomen decisiones que afectan a los grupos étnicos ${ }^{39}$. Esta exigencia aplica a las medidas de justicia, verdad, reparación y garantías de no repetición que tengan a estos grupos como potenciales beneficiarios. Tal situación es común pues muchos de los conflictos internos encuentran entre sus causas o efectos las tensiones étnicas y raciales, o victimizan a los grupos étnicos desproporcionadamente, pues su discriminación tradicional los hace más vulnerables a violaciones de derechos. El caso colombiano arroja lecciones interesantes al respecto.

En el 2011, en el marco de la discusión parlamentaria sobre la ley de reparaciones de las víctimas del conflicto armado, el Gobierno realizó procesos de consulta con grupos indígenas, afrodescendientes y gitanos, con el fin de atender a sus particulares necesidades en materia de reparación a través de decretos reglamentarios con un enfoque diferencial. Las consultas tuvieron diversos grados de éxito en términos de incidencia según la percepción de los grupos consultados, que en buena medida se explican por el nivel de organización previa de cada uno. Así, las organizaciones indígenas lograron más incidencia que las afrodescendientes a través de la consulta previa, dada la mayor capacidad de articulación de intereses y de logro de consensos comunes de aquellas. Como sea, las necesidades de estos grupos obtuvieron un espacio protagónico en el diseño de la regulación, que difícilmente habría existido si la ley de reparaciones se hubiera discutido únicamente a través del proceso ordinario.

A pesar de las potencialidades que tiene la participación de las víctimas en los procesos judiciales, son pocas las experiencias que ofrecen ejemplos de espacios amplios para su ejercicio. La experiencia de la CPI ha sido emblemática en su intento por alejarse del esquema penal centrado en el victimario y abrir espacios distintos de los ordinarios para la participación las víctimas y la sociedad civil. En efecto, el procedimiento de la CPI prevé que las víctimas participen en el desarrollo de las

39 Galo Galarza Paz. "Justicia y derecho en la administración de justicia indígena”, en Judith Salgado (comp.), Justicia indígena: aportes para un debate, Quito, UASB y Programa Andino de Derechos, 2002 . 
audiencias; además, permite que las organizaciones no gubernamentales presenten amicus curiae, obtengan en algunos casos el estatus de observadores, sirvan de fuente de información de los crímenes investigados, e incluso asistan directamente el trabajo de la CPI. No obstante, las experiencias participativas en los procesos de la CPI no han estado exentas de dificultades, en especial en relación con las víctimas, cuya participación ha sido hasta la fecha mucho más baja de lo esperado.

Esto se explica porque el procedimiento impone altas exigencias de representación legal que resultan difíciles de satisfacer debido a barreras del lenguaje, así como por la complejidad del formato de aplicación para el reconocimiento como víctima, la ausencia de ayuda legal y económica para realizar la aplicación, y la falta de medidas de protección. Estas limitaciones salieron a la luz en el caso de Uganda. Pese a la reticencia de la sociedad frente a la intervención de la Corte, 49 personas aplicaron para ser reconocidas como víctimas dentro del proceso abierto en 2006, pero casi un año después se aprobó la participación de tan solo cuatro de ellas, y sobre las demás, se alegaron cuestiones relacionadas con la falta de prueba sobre su identidad.

El caso colombiano también ofrece un ejemplo problemático de la participación de las víctimas en los procesos judiciales. La Ley de Justicia y Paz antes mencionada contempló audiencias de versión libre en las que las personas desmovilizadas debían contribuir a la verdad mediante la confesión de los hechos en los que hubieran participado o de los que tuvieran conocimiento.

Las víctimas y organizaciones de derechos humanos disputaron el rol preponderante que los victimarios tenían en las audiencias y la manera como utilizaron estos espacios para justificar sus crímenes. Insistieron ante la Fiscalía en que las víctimas y sus representantes deberían ser autorizados para ingresar a las audiencias e intervenir directamente en ellas. Igualmente, exigieron que se les diera apoyo económico para acudir a las audiencias y que se adecuaran los espacios para que se hicieran presentes. En un momento avanzado del proceso, la Fiscalía comenzó a hacer transmisión de las audiencias de versión libre en los municipios afectados por la violencia, pero en general el proceso recibió duras críticas por la poca voz y participación que se dio a las víctimas ${ }^{40}$.

El caso colombiano ofrece un ejemplo interesante pero problemático de participación de las víctimas en la definición judicial de sus reparaciones ${ }^{41}$. El ejemplo es interesante porque, a diferencia de la mayoría de procesos judiciales ordinarios, la Ley de Justicia y Paz creó un espacio específico de participación en el cual las

40 César Rodríguez Garavito y Meghan L. Morris, Hacer justicia en tiempos de transición: el papel del activismo y las instituciones en el fortalecimiento democrático, Buenos Aires, Siglo XXI, 2019.

41 Isabel Turégano Mansilla. La justicia de transición: concepto, instrumentos y experiencias, Bogotá, Universidad del Rosario, 2019. 
víctimas y los victimarios podrían intentar llegar a un acuerdo sobre el monto y la forma de la reparación antes de la decisión judicial. Esta tendría en cuenta el acuerdo en caso de ser alcanzado o, de lo contrario, ordenaría reparaciones con base en las consideraciones del juez (que podría tener en cuenta las demandas de la víctima). El problema de la etapa conciliatoria es que no se previeron mecanismos para evitar que la relación desigual de poder existente entre víctimas y perpetradores se reprodujera en la negociación, de modo tal que las víctimas no se sintieran amedrentadas para expresar sus demandas.

Dicha relación de poder es particularmente problemática en el caso colombiano, dado que los procesos de justicia se iniciaron en medio del conflicto, con lo cual las posibilidades de amenaza y retaliación fueron enormes. En esa medida, la participación de las víctimas requería un esquema de protección adecuado, y quizás habría funcionado mejor si estas no hubieran tenido que enfrentar al victimario de manera directa.

En Colombia, la ley de reparaciones adoptada en 2011 (conocida comúnmente como Ley de Víctimas ${ }^{42}$ ) dispone el deber de garantizar la elección de representantes de víctimas en todas las instancias de decisión previstas en la ley.

Así pues, se crearon mesas de participación de víctimas (MPV) en los niveles municipal, departamental y nacional, que ofrecen espacios para la discusión, interlocución, retroalimentación, capacitación y seguimiento de las disposiciones de la ley. Estas mesas tienen asiento (y por tanto voz y voto) en el Sistema Nacional de Atención y Reparación a Víctimas (SNARIV), que es el encargado de implementar la ley de reparaciones.

El SNARIV cuenta con dos unidades, y en ambas participan las víctimas elegidas por las MPV: la Unidad Administrativa Especial de Gestión de Restitución de Tierras, dedicada exclusivamente a la devolución de las tierras despojadas, ordenada por la ley, y la Unidad de Víctimas, encargada de aplicar todas las demás medidas de reparación y asistencia previstas por la ley. La Unidad de Tierras está dirigida por un Consejo Directivo del cual harán parte dos representantes de las víctimas escogidos por la MPV nacional, dos representantes de comunidades indígenas elegidos por la Mesa Permanente de Concertación de Pueblos Indígenas ${ }^{43}$ y dos representantes de comunidades negras, afrodescendientes, raizales y palenqueras -los raizales son un grupo afrocolombiano que habita el archipiélago de San Andrés, Providencia y Santa Catalina; los palenqueros son un grupo descendiente de los esclavos que escaparon y se asentaron en palenques o pueblos de esclavos fugados.

42 Antonio Iáñez Rodríguez. Mujeres y violencia en Colombia: la reparación a las víctimas del conflicto armado, Madrid, Los Libros de la Catarata, 2019.

43 Beatriz Kalinsky. “'No matarás’: el delito en la diversidad cultural”, en David Baigún (dir.). Pena y Estado, justicia criminal en las comunidades indígenas, Buenos Aires, Editores del Puerto, 1999. 
El caso chileno ofrece un ejemplo de los problemas que pueden surgir cuando las reparaciones colectivas no son diseñadas con la participación de las comunidades beneficiarias. En efecto, el diseño e implementación de las medidas de reparación no contó con la participación de los pueblos de origen mapuche. Dado que esas medidas consistieron fundamentalmente en reparaciones monetarias, su implementación parece haber tenido impactos negativos en las redes comunitarias y lazos de solidaridad de esos pueblos, que tenían una estructura de supervivencia e intercambio poco monetarizada.

En materia de las reparaciones individuales, tanto judiciales como administrativas, pueden abrirse espacios para que las víctimas expresen sus percepciones sobre los daños sufridos y presenten sus demandas concretas sobre la manera como consideran que deben ser reparadas. Para ello es importante que se establezcan requisitos para que los órganos decisorios tengan efectivamente en cuenta dichas demandas en sus decisiones. En materia de reparaciones colectivas se abren más posibilidades para la participación de los grupos afectados, y es deseable que sean estos quienes lideren la manera como los daños ocasionados a la colectividad pueden ser reparados.

En resumen, consideramos que la participación en las medidas de justicia transicional puede tener los objetivos de expresión, incidencia y transformación de las relaciones de poder, y que todos ellos pueden ser perseguidos de manera complementaria con el fin de asegurar el máximo nivel de participación posible y un nivel de expectativas razonable frente a lo que se puede esperar de estos mecanismos.

Es indispensable que quienes toman las decisiones sobre el modelo o las medidas de justicia transicional tengan claros los objetivos que la participación puede lograr para que sepan balancear las expectativas de los diversos sectores que generalmente están en pugna en este tipo de escenarios, y que lo hagan de manera democrática para que la participación contribuya al doble propósito del reconocimiento de las víctimas y su inclusión en la toma de decisiones como sujetos políticos activos con plenos derechos.

\section{CONCLUSIÓN}

Para concluir, hay que subrayar una vez más el apoyo de la fiscal de la CPI al proceso de paz y a la implementación de medidas idóneas de justicia transicional en Colombia. Por ejemplo, apoyó los esfuerzos de Colombia para poner fin al conflicto armado en este país desde el comienzo de las negociaciones de paz, de conformidad con los principios y valores del ER, y continuará haciéndolo durante la fase de su implementación. La existencia del ER es testimonio del deseo de la comunidad internacional de poner fin a la impunidad de los perpetradores de los crímenes más graves.

En la situación que ha afectado a Colombia y su pueblo tan profundamente, la forma en que la JEP asegure la rendición de cuentas para los crímenes más graves será de una importancia capital, tendrá a su disposición el marco jurídico nacional e internacional. 
Mediante el establecimiento de directrices claras y transparentes para la selección y priorización de casos, la JEP generará confianza en su trabajo, y podrá responder a las necesidades de las víctimas y de la sociedad en su conjunto.

Por su parte, la Fiscalía deberá cumplir su mandato con arreglo al ER. Esto incluirá asegurarse que la variedad de medidas de justicia transicional aplicadas en la situación en Colombia cumpla, de manera genuina, los objetivos del ER de poner fin a la impunidad y contribuir a la prevención. Estos objetivos son objetivos que Colombia comparte, como Estado Parte del ER. El enfoque que Colombia ha adoptado para asegurar la rendición de cuentas es innovador, complejo y ambicioso, y debe ser sostenido.

La Fiscalía sigue poniendo a disposición de las autoridades colombianas, con el fin de brindar cualquier apoyo, que está dentro de sus facultades a efectos de asegurar que se rompa el ciclo de impunidad y que los crímenes de guerra y los crímenes de lesa humanidad presuntamente cometidos durante el conflicto armado no queden sin castigo. A nuestro juicio, se deben estimular los debates públicos relativos a las normas de derechos humanos encaminadas a reforzar una transición a la democracia. No obstante, un proceso democrático no puede transformar una amnistía que por algún motivo sería nula en una amnistía lícita.

La verdad, la justicia y las reparaciones son complementarias y no respuestas alternativas a las violaciones graves de derechos humanos y las violaciones graves del derecho internacional humanitario. Si bien en algunos casos la plena revelación de la verdad por una persona acerca de las violaciones puede justificar una reducción de la sentencia, las medidas relativas a la justicia de transición, como el establecimiento y la actividad de una comisión de la verdad, no deben exonerar totalmente a los autores de un juicio penal a cambio de su testimonio, incluso cuando se reduce a cambio de una confesión plena, la pena impuesta a una persona responsable de violaciones graves de derechos humanos o del derecho humanitario debe ser proporcional a la gravedad del delito, y no se debe menoscabar el derecho de las víctimas a un recurso efectivo.

Proporcionar a las víctimas reparación por violaciones de derechos humanos y del derecho humanitario no reduce la obligación del Estado de velar por el enjuiciamiento de los crímenes de guerra y de las violaciones manifiestas de derechos humanos, mismo cuando se usan las amnistías para fomentar el desarme, desmovilización y reintegración de combatientes, los Estados no pueden otorgar amnistías incompatibles con sus obligaciones jurídicas internacionales.

En definitiva, los Estados son los creadores de las normas jurídicas internacionales, a la vez que receptores de ellas y actores a la hora de aplicarlas y reivindicar justicia. Por lo tanto, a pesar de la extensa normativa internacional y de los análisis y recomendaciones del relator especial acerca de la situación de los derechos humanos en el contexto de la justicia transicional, los avances en esta materia dependen 
esencialmente de la respuesta de los gobiernos y de la sociedad. Las autoridades estatales deben tomar las medidas necesarias para castigar a los culpables, reconocer los derechos de las víctimas y asegurar la no repetición de las violaciones cometidas en el pasado, procurando mantener a la vez el delicado equilibrio entre los mandatos jurídicos internacionales que exigen verdad, reparación y justicia para las víctimas y la necesidad de conservar la paz y el orden social.

A nuestro juicio, para que la justicia transicional tenga algún sentido, los gobiernos no pueden esquivar sus obligaciones legales, éticas y políticas con respecto a sus ciudadanos. Sin embargo, existen demasiados ejemplos en que los acuerdos de justicia transicional se negocian a puerta cerrada y con muchas cosas que ocultar.

La experiencia demuestra que las sociedades que no se enfrentan a las violaciones masivas de los derechos humanos suelen quedar divididas, lo cual genera desconfianza hacia las instituciones públicas y obstaculiza la transición hacia la democracia y el Estado de derecho.

En efecto, los avances recientes en el ámbito del derecho internacional no se han observado en los ámbitos estatales. Se encuentra que en la mayor parte de las experiencias analizadas las reparaciones no han logrado su finalidad de unificar e integrar las sociedades.

Así las cosas, estamos lejos de lo que parece ser el ideal de justicia transicional: reparar y pedir perdón a las víctimas, identificar y localizar los restos de los desaparecidos, reescribir las páginas de historia falsificadas y llevar a cabo reformas legales e institucionales en concordancia con los nuevos estándares de las normas internacionales de derechos humanos.

\section{REFERENCIAS}

Amaya, Jorge Alejandro. Justicia Transicional, Medellín, Universidad de Medellín, 2018.

Ambos, Kai; Francisco Cortés Rodas y John Zuluaga. Justicia transicional y derecho penal internacional, Bogotá, Siglo del Hombre Editores, 2018.

Archila, Mauricio. "Memoria e identidad en el movimiento indígena caucano", Una historia inconclusa, izquierdas sociales y políticas en Colombia, Bogotá, CINEP, 2009.

Ávila Santamaría, Ramiro. La justicia penal en la democracia constitucional de derechos, Quito, Universidad Andina Simón Bolívar, Corporación Editora Nacional, 2012, disponible en [http://repositorio.uasb.edu.ec/bitstream/10644/1090/1/CON003-\%C3\%81vila\%2c\%20R-La\%20in-justicia\%20penal\%20en\%20la\%20democracia.pdf]. 
Barona Becerra, Guido y Tulio Rojas Curieux. Teratologización y penalización: los fundamentos ideológicos de representación del indígena en la sociedad y justicia colombiana, Herinaldy Gómez y Cristóbal Gnecco (eds.), Universidad del Cauca, 2008.

Bautista Pizarro, Nathalia. "El significado de la pena en el marco de un proceso de paz. Reflexiones sobre el caso colombiano", disponible en [http://zis-online.com/ dat/artikel/2017_9_1131.pdf].

Chimbo Villacorte, Diego. "El error de prohibición en la justicia indígena”, Derecho Penal y Criminología, n. ${ }^{\circ}$ 37, 103, 2017.

Cote Barco, Gustavo Emilio; Catalina Ibáñez Gutiérrez, Nelson Camilo Sánchez, Diego Fernando Tarapués Sandino, Gonzalo Villa Rosas y John E. Zuluaga. Justicia de transición y Constitución I: análisis de la sentencia C-579 de 2013 de la Corte Constitucional, vol. 1, Bogotá, Temis, 2014.

Franco Mendoza, Moisés. La ley y la costumbre en la cañada de los once pueblos, México, Colegio de Michoacán, 1997.

Galarza Paz, Galo. "Justicia y derecho en la administración de justicia indígena", en Judith Salgado (comp.), Justicia indígena: aportes para un debate, Quito, UASB y Programa Andino de Derechos, 2002.

Giraldo Ramírez, Jorge. La tercera realidad: escritos sobre paz, reconciliación y derecho humanitario, Sílaba Editores, 2016.

Gómez Pavajeau, Carlos. La justicia transicional en los acuerdos de La Habana y sus especificidades, Bogotá, Universidad Externado de Colombia, 2017.

Halbwachs, Maurice. La memoria colectiva, Zaragoza, Prensas Universitarias, 2004.

Hernández Calderón, Cristian Daniel. Los fines de las penas alternativas en los procesos de justicia transicional. El caso colombiano, tesis de grado, Bogotá, Universidad Santo Tomás, disponible en [http://repository.usta.edu.co/].

Iáñez Rodríguez, Antonio. Mujeres y violencia en Colombia: la reparación a las víctimas del conflicto armado, Madrid, Los Libros de la Catarata, 2019.

Kalinsky, Beatriz. “"No matarás': el delito en la diversidad cultural”, David Baigún (dir.). Pena y Estado: justicia criminal en las comunidades indígenas, Buenos Aires, Editores del Puerto, 1999.

Mallinder, Louise. Amnesty, Human Rights and Political Transitions: Bridging the Peace and Justice Divide, Oxford, Hart Publishing, 2008, 30. 
Mejía Azuero, Jean Carlo. La Corte Penal Internacional y las Fuerzas Armadas de Colombia: una mirada desde la trinchera, Biblioteca Jurídica Diké, 2006.

Melamed Visbal, Janiel David. Justicia transicional en Colombia: huellas literarias sobre el fundador de las FARC, Barranquilla, Universidad del Norte, 2019.

Molinares Hassan, Viridiana. Guerra irregular y constitucionalismo en Colombia, Barranquilla, Universidad del Norte, 2014.

Orentlicher, Diane. "Settling accounts: the duty to prosecute human rights violations of a prior regime", en Yale Law Journal, vol. 100, n. 8 (1991), 2537.

Paredes, César. "Lamento indígena", en Semana, julio 9 de 2007, disponible en [http://www.semana.com/wf_InfoArticulo.aspx?IdArt=104887].

Pazmiño, Ernesto. Cuadernos para la interculturalidad, n. ${ }^{\circ}$ 10, Quito, Defensoría Pública, 2013.

Perdomo Poveda, Alberto. "Algunas consideraciones sobre la cláusula remisoria de la Ley 1922 de 2018, por medio de la cual se adoptan unas reglas de procedimiento para la Jurisdicción Especial para la Paz”, en Temas Socio-Jurídicos, 38 (77), 2019.

Perdomo Poveda, Alberto. Problemas hermenéuticos de la Ley de Amnistía - Especial referencia a la amnistía de iure consagrada. Bogotá, Ediciones Nueva Jurídica, 2017.

Pizarro, Eduardo. Cambiar el futuro, Penguin Random House, Colombia, 2017.

Quintero Mendoza, Juan Sebastián. Las desapariciones forzadas y los "falsos positivos": del derecho internacional al derecho administrativo colombiano, Bogotá, Universidad del Rosario, 2016.

Ricoeur, Paul. La memoria, la historia, el olvido, México, Fondo de Cultura Económica, 2008.

Rodríguez Garavito, César y Meghan L. Morris. Hacer justicia en tiempos de transición: el papel del activismo y las instituciones en el fortalecimiento democrático, Buenos Aires, Siglo XXI Editores, 2019.

Russell-Brown, Sherrie. "Out of the crooked timber of humanity: the conflict between South Africa's Truth and Reconciliation Commission and international human rights norms regarding effective remedies", en Hastings International and Comparative Law Review, vol. 26, n. ${ }^{\circ}$ 2, 2003, 227. 
Tarapués Sandino, Diego Fernando; Juana Acosta López, María Carmelina Londoño Lázaro y John E. Zuluaga. Justicia de Transición y Constitución II: análisis de la sentencia C-577 de 2014 de la Corte Constitucional, vol. 2, Bogotá, Temis, 2015.

Traverso, Enzo. El pasado, instrucciones de uso: historia, memoria, política, Madrid, Marcial Pons, 2007.

Uprimny, Rodrigo. "Los retos jurídicos de la desaparición forzada: de la lucha por el reconocimiento a la lucha por la eficacia de un crimen atroz", en Razones y emociones, disponible en [http://www.dos-mundos.org/pdf/revista/sinras 018.pdf].

Villa, William y Juan Houghton. Violencia política contra los pueblos indígenas de Colombia 1974-2004, Medellín, Alto Vuelo Editores, 2005.

Williamson, Jaimie Allan. "Reflexiones acerca de la responsabilidad del mando y la responsabilidad penal", en $R I C R, \mathrm{n} .^{\circ} 869,2008,145-165$.

Wood, Elisabeth. "La violencia sexual en el marco de conflictos armados: hacia un entendimiento de su variación”, en Análisis Político, vol. 22, n. . 66, Bogotá, mayo/ agosto 2009.

Zaffaroni, Raúl. Tratado de Derecho Penal, tomo v, Buenos Aires, Ediar, 1999.

\section{En línea}

[https://www.jep.gov.co/Infografas/brochure.pdf] - casos abiertos en la JEP.

[https://www.icc-cpi.int/NR/rdonlyres/3D3055BD-16E2-4C83-BA8535BCFD2A7922/285202/OTP2012035032COLResumenEjecutivodelReporteIntermed.PDF] - Informe intermedio de la JEP.

[http://www.oas.org/es/cidh/mandato/Basicos/PrincipiospPL.asp] - Definición de responsabilidad de mando.

[https://www.ictj.org/es/que-es-la-justicia-transicional] - Justicia Transicional.

[http://www.icc-cpi.int/iccdocs/otp/OTP-Hon-Col-2014.PDF].

[www.alfonsozambrano.com/doctrina.../dp-errortipo_errorprohicion.doc].

[http://www.suin-juriscol.gov.co/viewDocument.asp?ruta=Leyes/1685991].

[https://www.corteconstitucional.gov.co/relatoria/2019/C-112-19.htm]. 
[https://www.unidadvictimas.gov.co/sites/default/files/documentosbiblioteca/nuevo acuerdofinal.pdf].

[https://www.oas.org/juridico/spanish/mesicic2_col_ley_5_sp.pdf] - Ley 5/92.

[www.corteconstitucional.gov.co/relatoria/2002/C-578-02.htm] - Sentencia C- 178/02.

[www.suin-juriscol.gov.co/viewDocument.asp?ruta=Leyes/1675282] - Ley 1180 de 2007, por medio de la cual se aprueba el "Acuerdo sobre los Privilegios e Inmunidades de la Corte Penal Internacional”.

[www.suin-juriscol.gov.co/viewDocument.asp?ruta=Leyes/1676652] - Ley 1268 de 2008, "reglas de procedimiento y prueba" y los "elementos de los crímenes de la Corte Penal Internacional”, aprobados por la Asamblea de los Estados Parte de la Corte Penal Internacional, en Nueva York, del 3 al 10 de septiembre de 2002. 